\title{
Equitable representation in councils: theory and an application to the United Nations Security Council
}

\author{
Matthew Gould ${ }^{1} \cdot$ Matthew D. Rablen ${ }^{2}$
}

Received: 10 September 2015/Accepted: 28 August 2016/Published online: 13 September 2016

(C) The Author(s) 2016. This article is published with open access at Springerlink.com

\begin{abstract}
We analyze democratic equity in council voting games (CVGs). In a CVG, a voting body containing all members delegates decision-making to a (time-varying) subset of its members, as describes, e.g., the relationship between the United Nations General Assembly and the United Nations Security Council (UNSC). We develop a theoretical framework for analyzing democratic equitability in CVGs at both the country and region levels, and for different assumptions regarding preference correlation. We apply the framework to evaluate the equitability of the UNSC, and the claims of those who seek to reform it. We find that the individual permanent members are overrepresented by between 21.3 times (United Kingdom) and 3.8 times (China) from a country-level perspective, while from a region perspective Eastern Europe is the most heavily overrepresented region with more than twice its equitable representation, and Africa the most heavily underrepresented. Our equity measures do not preclude some UNSC members from exercising veto rights, however.
\end{abstract}

Keywords United Nations Security Council · United Nations · Voting power · Square-root rule $\cdot$ Equity

JEL Classification D72 $\cdot$ D71 $\cdot$ C71 $\cdot$ C63

Matthew Gould

gouldma@westminster.ac.uk

Matthew D. Rablen

m.rablen@sheffield.ac.uk

1 Westminster Business School, University of Westminster, 35 Marylebone Road, London NW1 5LS, UK

2 Department of Economics, University of Sheffield, 9 Mappin Street, Sheffield S1 4DT, UK 


\section{Introduction}

Decision-making within international organizations is sometimes made by voting bodies that comprise a proper subset of the membership (a "council"). The pre-eminent such council, and the primary motivator of this paper, is the United Nations Security Council (UNSC), the only international body with the power to authorize the use of armed force. At any one time, the UNSC contains only 15 members from a total United Nations (UN) membership of 193. Two further councils operating within the UN are the United Nations Economic and Social Council (ECOSOC) and the United Nations Human Rights Council (UNHRC). ECOSOC (54 members) is responsible for coordinating the work of $14 \mathrm{UN}$ specialized agencies, including the World Bank and the International Monetary Fund, while the UNHRC (47 members) is responsible for promoting and protecting human rights around the world. Councils also operate within many of the UN's specialized agencies, some examples being the Board of Governors of the International Atomic Energy Agency (35 members), the Council of the International Maritime Organization (40 members), and the Executive Board of the World Health Organization (34 members). ${ }^{1}$

In this paper we develop a simple and sober theoretical framework for analyzing democratic equitability in councils and present an application to the UNSC. Existing studies of equity in international voting bodies are predicated on an idealized two-stage democratic decision-making process-first, each member state holds a national vote; second, a delegate from each member state votes in the international body according to the outcome of the national vote. International voting bodies that have been analyzed in this framework include the Council of the European Union (e.g., Felsenthal and Machover 2001, 2004, 2007; Laruelle and Widgrén 1998; Leech 2002a); the UN General Assembly (Manno 1966; Newcombe et al. 1971; Dixon 1983), the IMF Executive Board (Leech 2002b; Leech and Leech 2013; Rapkin and Strand 2006), and the World Bank Executive Boards (Leech and Leech 2005). ${ }^{2}$ The UNSC is notably absent from this list.

What lies behind this lacuna? When international decision-making is by a council, the conventional democratic decision-making process described above cannot be applied directly for at least two reasons. First, in a council, only a subset of country delegates gets to participate in the international vote. Second, this subset is not usually constant over time. We account for these factors in a new class of voting game we term a council voting game (CVG). In a CVG a body comprising all members - an "assembly" — assigns (by election or otherwise) a subset of its members to a "council". As the council's membership must be allowed to change through time we cannot take it to be a primitive, thus distinguishing a CVG from the classical "simple voting game" of Shapley (1962). In a CVG the set of council members instead originates endogenously as a function of four primitive elements, $(A, N, R, P)$, where $A$ is the set of members of the assembly; $R$ is a regional partition on

\footnotetext{
1 Why do councils exist? In the case of military or emergency action, the lengthy deliberations of a large body are thought to prevent such a body from being able to react with sufficient speed to developing security threats. Alternatively, councils may function in domains deemed to require detailed or specialised analysis (ECOSOC being an example). From a realpolitik perspective, it is also possible that councils are a mechanism by which countries with greater stakes in the decisions being taken seek to acquire greater influence. Councils can also arise at the national level. For instance, some countries have "Privy" or "Executive" Councils with the right to enact legislation during states of emergency, committees that perform detailed tasks such as voting over proposed new legislation on a clause-by-clause basis prior to final approval by the national legislature, or both.

2 Applications to national legislatures include Miller (2009) and Banzhaf (1968) to the US Electoral College; and McLean et al. (2005) and Dunleavy (2010) to the UK Parliament.
} 
$A$ (the UN membership is partitioned into five regions, for instance); $N$ is a partition of seats on the council between regions, and $P$ is a stochastic process that determines the probability with which each member of $A$ is assigned to the council.

To analyze equitable representation, we embed a CVG within a democratic decisionmaking process. In the conventional two-stage process employed in the literature, the first (national) vote is held under a simple majority rule, with a binary set of voting possibilities \{for, against , and a dichotomous outcome space \{mandate to vote "for", mandate to vote "against" $\}$. In the second (international) stage, countries vote "for" or "against" according to their national mandates and the outcome space is \{pass, fail\}. We generalize this process in three ways. First, we posit a tripartite process in which a national vote occurs in the first stage, countries are assigned randomly to the council in the second stage, and the council votes in the final stage. Second, we allow for the first stage to be a regional (rather than national) vote to study a notion of equity at the level of regions, distinct from equity at the level of countries. Last, in order to represent the distinct role of abstention in councils such as the UNSC faithfully, we generalize the set of voting possibilities and outcomes in the national and international votes, and we generalize the decision rule beyond simple majority rule. ${ }^{3}$

Our basic normative notion of democratic equity-the equalization of expected voting power (EVP) criterion-requires that every citizen have the same voting power (in expectation) over outcomes in the council, before the assignment of countries to the council is known. ${ }^{4}$ This concept of equity, therefore, reflects both a country's voting rights when serving as a council member, and how often it is a council member.

We distinguish between equity at the country and region levels: the country-level equity concept presupposes that, when a member of the council, countries represent only their own citizens, whereas the region-level concept presupposes that, when a council member, countries act as representatives of their region as a whole. We also develop flavors of the EVP criterion under different a priori assumptions regarding intra-regional preference correlation. Interestingly, our country and region equity concepts are not, in general, mutually compatible: a CVG that is equitable if council members represent only themselves (as opposed to their regions) will necessarily fail to achieve equitable regional representation, and the reverse also is true.

We characterize democratic equitability under each of our equity concepts. Under the assumption of random voting, we show that our country equity concept is satisfied when a citizen's expected absolute voting power in the council (before the assignment of countries to the council is known) is inversely proportional to their absolute voting power in the national ballot. Regional equity under random voting requires that a citizen's absolute voting power in the council (when each region votes as a bloc) is inversely proportional to their absolute voting power in the regional ballot.

With respect to applications, our paper is the first we are aware of to present a quantitative assessment against formal equity concepts of the equitability of the UNSC for both individual countries and regions. As we discuss in more detail in Sect. 3, the UNSC is witnessing a protracted reform debate that centers on national and regional representation (see, e.g., Franck 2003). At the regional level, reformers argue that Africa and Asia have

\footnotetext{
3 Thus, we contribute to the growing literature on the theory and application of ternary voting games (see, e.g., Birkmeier et al. 2011; Braham and Steffen 2002; Côrte-Real and Pereira 2004; Felsenthal and Machover 1997; Freixas 2012; Freixas and Zwicker 2003, 2009; Herrera and Mattozzi 2010; Lindner 2008; Uleri 2002).

4 We shall use the terms "equitability" and "equity" synonymously throughout.
} 
too little power, and that a north-south imbalance exists. At the national level, countries such as Germany and Japan-who are eligible only for Non-Permanent Member (NPM) status on the UNSC — claim to be severely underrepresented, and the permanent members (PMs) — who each wield an individual veto-are argued to have too much representation.

Our modeling of the UNSC utilizes a specification of the democratic decision-making process in which the vote in the first stage is under an extension of the well-known majority threshold rule to allow for three voting possibilities, \{for, abstain, against\}, and three possible outcomes, \{mandate to vote for, no mandate, mandate to vote against . Specifically, a threshold proportion of the eligible voters must vote for (against) a motion for a country to have a mandate to vote for (against) a motion in the council. Abstention in the council is identified with instances wherein a country fails to obtain a mandate for voting either for or against a motion in the national vote. We prove an extension of Penrose's (1946) square-root law for the case in which the majority threshold is set at one-third of eligible voters.

Our findings give detailed insights into the UNSC reform debate. Our main notion of country equity shows that the permanent members (PMs) are heavily overrepresented: the United Kingdom is the most heavily overrepresented PM with over 21 times its equitable level of expected voting power, while China is the least heavily overrepresented PM with around 3.8 times its equitable level of expected voting power. Our equity concepts do not, however, preclude some countries holding a right of veto. The very smallest countries in terms of population suffer from very significant underrepresentation-Dominica, for instance, is estimated to receive just $0.8 \%$ of its equitable voting power. Our regional equity concept shows that Africa is the most underrepresented region with only around one-third of its equitable voting power, while Eastern Europe is the most overrepresented with just over double its equitable representation. These findings suggest a case for a reallocation of the seats given to each region, and our notion of country equity is prescriptive in this regard.

The plan of the rest of paper is as follows: Sect. 2 develops a theoretical framework for the analysis of democratic equity in councils; Sect. 3 presents an application of the theory to the UNSC; and Sect. 4 concludes. All proofs are located in the Appendix.

\section{Theory}

In this section we consider a setting in which an "assembly" assigns a subset of its members to a "council". As with other aspects of the model, this setting is intended to mirror the UN's observed structure, in which context the assembly should be thought of as the UN General Assembly (UNGA), the main deliberative body of the UN containing all 193 of its members, and the council could refer to any of the councils within the UN identified in the Introduction. As in the UNGA, we partition the assembly's membership into regional groups. Countries are then assigned to the council in fixed numbers from each of the regions.

Alternative interpretations of these elements of the model are possible, however. For instance, the assembly could be a national legislature partitioned along party-political (rather than geographic) lines, and the council a cross-party committee of the legislature. 


\subsection{Council voting games}

In this section we develop formally a class of voting games we term a council voting game (CVG). We begin by describing the elements of a CVG.

Let the assembly (comprising all members) be denoted as the finite set $A$. We partition $A$ into regions by writing $A=\cup_{j} R_{j}$, where $R_{j}$ is the $j$ th region, $j \in J$. The set of all regions, $\left\{R_{j}\right\}_{j \in J}$, we denote by $R$. Each region is a set of countries; we define $a_{i j}$ as the $i$ th country within region $j$.

The number of council seats for the members of each region $j$ is given by $n_{j} \geq 1$, where it is assumed that the number of seats for each region is always smaller than the number of countries belonging to the region, $\left|R_{j}\right|>n_{j}$. The set $\left\{n_{j}\right\}_{j \in J}$ we denote $N$.

Rather than specify the procedure by which countries are assigned to the council, we adopt a reduced form representation that allows for any such procedure. An assignment process $P$ is a stochastic process that induces, for every motion $k$ on which the council must vote, a probability $p_{i j k}$ that country $a_{i j}$ is assigned to the council for that vote. Under $P$, the average assignment probability of country $a_{i j}$ on an infinite set of motions $k \in K$ is given by $\bar{p}_{i j}=\mathbf{E}_{K}\left(p_{i j k}\right)$.

The above elements together determine the set of council members, $M$, voting on a given motion. Hence, we write $M \equiv M(A, N, R, P)$. The realized set of council members voting on motion $k$ is signified by $M_{k}$, and we denote by $M_{j k}$ the intersection $M_{k} \cap R_{j}$.

Votes in the council are decided according to a decision rule $U$, which is a mapping from the space of voting possibilities to an outcome space, satisfying the monotonicity conditions given in Freixas and Zwicker (2003). ${ }^{5}$ We may now define a CVG:

Definition 1 A council voting game is the pair $\mathcal{C}=\{M, U\}$.

\subsection{Equity in CVGs}

\subsubsection{The democratic decision-making process}

To understand the equity properties of a CVG, it must be embedded in a democratic decision-making process that maps the preferences of citizens to outcomes. To analyze differing country and regional notions of equity, we introduce two such decision-making processes: the "country" process (CDP) and the "region" process (RDP). Under the CDP countries on the council represent only their national populations, allowing us to investigate equity at the country level. Under the regional process (RDP), countries are assumed a priori to act on the council as regional representatives, permitting us to investigate equity at that level.

For a given motion $k$, the CDP comprises three stages. In stage 1, a national ballot is held in each country. The decision rule in stage 1 is taken to be anonymous, such that every citizen of a country has symmetric voting rights. In stage 2 , a subset $M_{j k} \subset R_{j}$ of countries are assigned to the council from each region. In stage 3 , countries $a_{i j} \in M_{k}$ vote in the council according to the outcome of their national ballot in stage 1 . In contrast, in the RDP, a single regional ballot is held in each region in stage 1 under an anonymous decision rule, such that every citizen of a region has symmetric voting rights. In stage 2 a subset $M_{j k} \subset R_{j}$ of countries are assigned to the council from each region. In stage 3 , countries $a_{i j} \in M_{j k}$

\footnotetext{
${ }^{5}$ In particular, application of the decision rule identifies uniquely the set of winning coalitions.
} 
vote as a bloc, each bloc member voting according to the outcome of the regional ballot in stage $1 .^{6}$

\subsubsection{Equity concepts}

Our basic normative notion of democratic equity is that, from behind a veil of ignorance as to what a citizen's preference is, and to which country or region they belong, a citizen should be able to influence outcomes in the council equally. This criterion is often referred to as the "one-person, one-vote" criterion, or the "equalization of voting power" criterion (for brevity, the EVP criterion). Crucially, we require that the EVP criterion hold before the assignment of countries to the council occurs. That is, we require that expected voting power (before it is known which countries will vote in stage 3 ) to be equal across citizens. This notion of equity acknowledges that the democratic power of a citizen in a global council depends not only on the voting rights of his or her country when it is a member of the council, but also on how frequently his or her country is a member of the council. ${ }^{7}$

We posit two related forms of the EVP criterion. In its strong form, we require that the EVP criterion hold for each and every motion. This implies, for instance, that a country with a smaller assignment probability on a given motion must, by way of compensation, receive more voting power on the council if it is assigned. ${ }^{8}$

The weak form of the EVP criterion, however, allows for deviations from the EVP criterion on any one ballot, so long as deviations offset across an infinite sequence of ballots. Intuitively, the weak form permits intertemporal shifting of assignment probabilities and voting rights: a country might, for instance, have guaranteed representation on the council in a given period in return for a lesser assignment probability in other periods. Under weak EVP, a country with a smaller average assignment probability must be compensated for longer expected spells outside the council by the exercise of greater voting power when it is a member of the council.

Two variants of country equity are therefore possible - one under the strong form of the EVP criterion $\left(C E_{s}\right)$, and one under the weak form $\left(C E_{w}\right)$. In many contexts, the question of whether a CVG is equitable on average over time is of primary interest. Accordingly, in the application we shall mainly employ the weak form of EVP. At minimum, however, the strong form can be used as a "tie-breaker" to choose between CVGs that stalemate with respect to weak EVP.

In contrast, when considering regional equity no meaningful distinction exists between evaluating the EVP criterion for every motion or across an infinite sequence of motions. This is so because each region always is represented on the council, and the identities of

\footnotetext{
6 As, in the context of regional equity, we are interested specifically in understanding the representation of regions as cohesive entities it is appropriate in this context to disregard the possibility-which might be very real in practice - that countries assigned to the council in stage 2 of the RDP might break ranks and vote according to the preference of their own citizens rather than according to the outcome of the regional ballot. This point underscores the need to understand both country and regional concepts of equity.

7 Several of the proposals for reforming the UNSC detailed in Cox (2009) modify only the assignment probabilities, leaving voting rights unchanged. This suggests that world leaders understand (at least intuitively) the importance of assignment probabilities distinct from voting rights.

8 Our notion of country equity is procedurally equitable, but is compatible with individual countries experiencing short-term gluts and droughts of membership owing to the stochastic nature of the assignment process. That is, we consider "procedural" equity, rather than "outcome" equity (see, e.g., De Cremer et al. 2010). This distinction is analogous to that made by scholars of law between "procedural" and "distributive" justice (e.g., Konovsky 2000); and by economists between "static" and "dynamic" equity (e.g., Rose and Stevens 1998).
} 
the countries that form the regional bloc are immaterial. Accordingly, only one notion of regional equity must be considered, which we denote by $R E$.

\subsubsection{Equity concepts-a formalization}

We denote the population of country $a_{i j}$ as $q_{i j} \in \mathbb{N}$, and the population of region $j$ as $q_{j}=\sum_{a_{i j} \in R_{j}} q_{i j}$. We denote the absolute voting power of a citizen of country $a_{i j}$ in stage 1 under the CDP (RDP) as $\varphi_{i j}^{\mathrm{CDP}}\left(\varphi_{j}^{\mathrm{RDP}}\right)$. Similarly, absolute voting power in stage 3 is denoted for country $a_{i j}$ under the CDP (RDP) as $\omega_{i j}^{\mathrm{CDP}}\left(\omega_{j}^{\mathrm{RDP}}\right) \cdot{ }^{9}$ Candidate specifications for $\varphi$ and $\omega$ are given in, e.g., Freixas (2005a, b), but at this stage we need not specify a particular index of absolute voting power.

Under the CDP, we denote the overall (or composite) voting power of a citizen of country $a_{i j}$ (before it is known whether $a_{i j}$ will be assigned to the council to vote on motion $k$ ) by $v_{i j k}^{C E_{s}}$, and the expectation of $v_{i j k}^{C E_{s}}$ over $k \in K$ is denoted $v_{i j}^{C E_{w}}$. Under the RDP, we denote the composite voting power of a citizen of region $j$ by $v_{j}^{R E}$.

Definition 2 below formalizes our three perspectives on the EVP criterion. Equality across countries/regions of the relevant notion of composite voting power is expressed mathematically as the requirement that all individual country/regional deviations from the Assembly mean, $\mathbf{E}_{A}(\cdot)$, be zero. This approach shall provide a natural metric for measuring deviations from each equity concept for the purposes of application.

\section{Definition 2}

(i) $\mathcal{C}$ satisfies $C E_{s}$ if $v_{i j k}^{C E_{s}}=\mathbf{E}_{A}\left(v_{i j k}^{C E_{s}}\right)$ for all $a_{i j}$ and all $k \in K$;

(ii) $\mathcal{C}$ satisfies $C E_{w}$ if $v_{i j}^{C E_{w}}=\mathbf{E}_{A}\left(v_{i j}^{C E_{w}}\right)$ for all $a_{i j}$;

(iii) $\mathcal{C}$ satisfies $R E$ if $v_{j}^{R E}=\mathbf{E}_{A}\left(v_{j}^{R E}\right)$ for all $a_{i j}$.

We begin by analyzing Definition 2 under the assumption-termed uncorrelated preferences (UC) - that every world citizen votes independently, and is equally likely to vote for each of the given voting possibilities. UC is not understood as denying the possibility of preference correlation in this context, but instead harks to Bernoulli's Principle of Insufficient Reason (BPIR), according to which voting alternatives should be assigned equal epistemic probabilities if there is no known reason for assigning unequal ones (see, e.g., Felsenthal and Machover 1997, 2003). ${ }^{10}$ An analysis under UC preferences captures the inequity that is inherent in the rules of a CVG, which is logically distinct from the actual, or empirical, level of inequity that might be observed at a point in time. Given the shifting sands of political ties over time, strong arguments exist for considering this concept of

\footnotetext{
9 Note that, under the CDP, a country's absolute voting power on the council, $\omega_{i j}^{\mathrm{CDP}}$, is motion-invariant, yet its relative voting power, $\omega_{i j}^{\mathrm{CDP}} / \sum_{a_{i j} \in M_{k}} \omega_{i j}^{\mathrm{CDP}}$, may vary from motion to motion. A similar point also applies to regional blocs under the RDP. In the UNSC, however, both absolute and relative voting power are motion-invariant (for countries and regions), but only because the rules of this particular council imply that a non-PM always is replaced by another such member from the same region with identical voting rights.

${ }^{10}$ Indeed, were preferences actually uncorrelated within countries and regions, then these concepts would be almost arbitrary and we would not witness the fierce debates over regional and national representation that we indeed observe in the UNSC reform debate.
} 
inherent, rather than empirical, inequity. Accordingly, we make UC preferences our benchmark assumption. As we shall discuss below, however, the assertion of BPIR may not be appropriate in all contexts, so we will examine later the implications of Definition 2 when allowing a priori for degrees of preference correlation.

For UC preferences it is straightforward to deduce that

$$
v_{i j k}^{C E_{s}}=\varphi_{i j}^{\mathrm{CDP}} p_{i j k} \omega_{i j}^{\mathrm{CDP}} ; \quad v_{i j}^{C E_{w}}=\varphi_{i j}^{\mathrm{CDP}} \bar{p}_{i j} \omega_{i j}^{\mathrm{CDP}} ; \quad v_{j}^{R E}=\varphi_{j}^{\mathrm{RDP}} \omega_{j}^{\mathrm{RDP}} ;
$$

which gives rise to our first Proposition:

Proposition 1 Under UC preferences, $\mathcal{C}$ satisfies

(i) $\quad C E_{s}$ if and only if $\omega_{i j}^{\mathrm{CDP}} \propto \frac{1}{p_{i j k} \varphi_{i j}^{\mathrm{CDP}}}$ for all $a_{i j}$ and all $k \in K$;

(ii) $\quad C E_{w}$ if and only if $\omega_{i j}^{\mathrm{CDP}} \propto \frac{1}{\bar{p}_{i j} \varphi_{i j}^{\mathrm{CDP}}}$ for all $a_{i j}$;

$$
R E \text { if and only if } \omega_{j}^{\mathrm{RDP}} \propto \frac{1}{\varphi_{j}^{\mathrm{RDP}}} \text { for all } j .
$$

According to parts (i) and (ii) of Proposition 1, country equity does not relate exclusively to the properties of the decision rule $U$, but rather is a property of the interaction between $U$ and the (stochastic) assignment process $P$. According to part (i), to meet the EVP criterion in its strong form it must hold that, for every motion, expected voting power on the council is assigned in inverse proportion to a citizen's expected voting power across stages 1 and 2 of the CDP. Many divisions of voting power and assignment probability that achieve strong EVP are possible: if the $p_{i j k}$ are equal across countries (a flat rule) then strong EVP holds if voting power in the council is proportional to $1 / \varphi_{i j}^{\mathrm{CDP}}$. An alternative possibility is that voting power in the council obeys a flat rule, and the assignment probabilities are proportional to $1 / \varphi_{i j}^{\mathrm{CDP}}$. $^{11}$

In its weak form, country EVP requires an understanding of the long-run properties of the assignment process, as summarized by $\bar{p}_{i j}$-the average assignment probability of country $a_{i j}$. Weak country EVP is met if, on average, expected voting power on the council is assigned in inverse proportion to a citizen's long-run expected voting power across stages 1 and 2 .

It is straightforward to observe that if the $p_{i j k}$ are made invariant with respect to $k$, then $p_{i j k}=\bar{p}_{i j}$ holds for all $k \in K$, such that strong country EVP coincides with weak country EVP. In all other cases, however, the two concepts are distinct; strong country EVP implies weak country EVP, but the reverse implication does not hold.

Last, part (iii) of the proposition establishes the following: regional equity requires that the voting power of regional bloc $j$ on the council must be inversely proportional to the voting power of a citizen of region $j$ in stage 1 . Assignment probabilities do not play a role here because each region always is represented on the council.

Are region and country equity mutually compatible? A complex relationship exists between the voting power of a bloc and the sum of the voting powers of its individual members when voting independently (see, e.g., Leech and Leech 2006). In general, this relationship is non-linear (and so also non-additive), yet compatibility of regional and

\footnotetext{
11 Both of these examples are monotonic in the sense that more populous countries receive weakly larger absolute voting power and assignment probability. We note, however, that $C E_{s}$ also is satisfied by a range of less empirically plausible rules in which, e.g., assignment probability is declining in population and voting power is a function of population that rises faster than $1 / \varphi_{i j}^{\mathrm{CDP}}$.
} 
country equity requires a proportional relationship to hold between the two. While artefactual examples can be constructed with this property, the probability of such a relationship happening to hold, by chance, in an empirical example seems remote. Accordingly, under UC preferences, country and regional equity are, for practical purposes, incompatible.

\subsection{Correlated preferences}

Reasons sometimes exist for supposing preference correlation at the country/region level, in which case it is inappropriate to invoke BPIR. In the context of a cross-party committee, for instance, voting down party lines may be anticipated a priori. ${ }^{12}$ We therefore outline two alternative possible configurations of citizen preferences. We stress, however, that the most appropriate configuration of preferences must be judged on a case-by-case basis depending on the council to which the theoretical model is being applied.

The first alternative, Region Correlation (RC), is the extreme case (relative to UC) in which all citizens of region $j$ have identical preferences, such that (i) voting is perfectly correlated across citizens within a country; and (ii) country voting outcomes are perfectly correlated across countries within a region. On a given motion, however, each voting possibility is equally likely to be the one chosen unanimously by all regional citizens, so voting outcomes between regions remain independent. Accordingly, under RC preferences, countries within each region vote as regional blocs on the council, but each bloc votes independently. As this outcome holds under both decision-making processes we consider, no meaningful distinction between country and regional equity arises in this case. Thus we may restrict attention to regional equity.

With RC preferences, every world citizen is a dictator in the stage 1 regional vote, in the standard sense that the outcome of the vote always coincides with his/her preferred outcome. A minimal property of all voting power indices of which we know is that a dictator receives the maximal voting power, which we denote by $\bar{\varphi}>0$. Thus, we may write: $v_{j}^{R E}=\bar{\varphi} \omega_{j}^{\mathrm{RDP}}$.

A second configuration, Country Correlation (CC), constitutes an intermediate case in which all citizens of country $i$ have identical preferences, but preferences are independent across countries. With CC preferences every world citizen is again a dictator in the national (stage 1) vote under the CDP; we thus obtain $v_{i j k}^{C E_{s}}=\bar{\varphi} p_{i j k} \omega_{i j}^{\mathrm{CDP}}$ and $v_{i j}^{C E_{w}}=\bar{\varphi} \bar{p}_{i j} \omega_{i j}^{\mathrm{CDP}}$. Citizens are not dictators in stage 1 under the RDP, however, so, as under UC preferences, we obtain $v_{j}^{R E}=\varphi_{j}^{\mathrm{RDP}} \omega_{j}^{\mathrm{RDP}}$. Noting that $\bar{\varphi}$ simply can be subsumed into the constant of proportionality we obtain:

\section{Proposition 2 Under $C C$ preferences $\mathcal{C}$ satisfies}

(i) $\quad C E_{s}$ if and only if $\omega_{i j}^{\mathrm{CDP}} \propto 1 / p_{i j k}$ for all $a_{i j}$ and all $k \in K$; and $C E_{w}$ if and only if $\omega_{i j}^{\mathrm{CDP}} \propto 1 / \bar{p}_{i j}$ for all $a_{i j}$;

(ii) $\quad R E$ if and only if $\omega_{j}^{\mathrm{RDP}} \propto 1 / \varphi_{j}^{\mathrm{RDP}}$ for all $j$;

and under $R C$ preferences $\mathcal{C}$ satisfies $R E$ if and only if $\omega_{j}^{\mathrm{RDP}}$ is equal for all $j$.

\footnotetext{
${ }^{12}$ More generally, whenever the partition between regions and/or countries involves some degree of selfselection, as opposed to exogenous assignment, an a priori expectation of some degree of preference correlation might be posited.
} 


\section{Application}

In this section we apply the theory of Sect. 2 to the case of the UNSC, the most powerful organ within the UN. The UNSC has the authority to make legally binding resolutions in fulfillment of its mandate to maintain international peace and security. To that end, it can suspend economic and diplomatic relations between countries, impose blockades, and authorize the use of armed force. Under the present arrangements-which have been in place since 1965-the UNSC is comprised of 15 members, of which five-China, France, Russia, the United Kingdom, and the United States-are ever-present and wield a veto on all non-procedural matters. The remaining ten non-permanent members are elected by the UNGA and serve time-limited two-year terms.

The UNSC is experiencing a protracted reform debate, in which both country and regional perspectives on equity are cited frequently (e.g., Russett et al. 1996; Hammer 2002; Schwartzberg 2003; Annan 2005; Blum 2005). From the country perspective, it is argued commonly that the veto rights of the five PMs gives these countries too much influence. Nearly all governments wish to abolish or limit the right of veto, which is viewed as an unfair and anachronistic legacy of the Second World War (Fassbender 2004; Schwartzberg 2003).

From the regional perspective, it is argued that Africa and Asia are underrepresented as together they account for around $75 \%$ of the populations of UNGA member countries, but are allocated only $20 \%$ of the PM seats, and $50 \%$ of the NPM seats, and, moreover, that an even larger representational imbalance exists between the developed north and the developing south.

In the absence of a formal theoretical framework for assessing the equitability of CVGs, or for addressing issues relating to regional- and country-specific notions of equity, existing quantitative analyses of equity in the UNSC are unable to verify these claims directly. Instead, extant studies use the voting power of a PM relative to a NPM as an informal indicator of equitability (see, e.g., Hosli et al. 2011; O’Neill 1996; Strand and Rapkin 2011; Straffin 1993, p. 180). The theoretical framework of Sect. 2 permits, for the first time, a formal quantitative assessment of the equitability of the UNSC for both individual countries and regions. The benchmark analysis is performed for UC preferences, although we shall comment briefly on the implications of assuming CC preferences.

Are our democratic notions of equity appropriate for a body such as the UNSC? After all, different countries make very different per capita contributions to peacekeeping and international disaster relief. ${ }^{13}$ There are, however, strong arguments for operating international organizations along democratic lines relating, in particular, to the need for such organizations to be seen as legitimate (Frey and Stutzer 2006; Stutzer and Frey 2006; Marchetti 2008; Cowling et al. 2010). Also, to our knowledge, an alternative equity notion with the philosophical clarity and widespread normative acceptability of the democratic notion of one person, one vote, is yet to be proposed. Last, as we comment further in the conclusion, even if implementation of the democratic equity concepts discussed here would violate implicit realpolitik constraints, these concepts still stand as benchmarks for identifying the optimal second-best choice from among the set of CVGs that satisfy such constraints.

\footnotetext{
13 As of 2014, the United States contributes $22 \%$ of the UN's regular budget, Japan contributes $10.8 \%$, and Germany $7.1 \%$, whereas the combined contributions of African nations sum to only $1.2 \%$ (UN Secretariat 2013). Contributions to the UN's peacekeeping budget are even more skewed towards developed countries.
} 


\subsection{Modeling the UNSC}

We consider the UNSC as of 2012; the corresponding CVG we denote by $\mathcal{C}_{\mathrm{UNSC}}^{2012}$. We now describe each of the elements $(A, N, R, P, U)$ for this game. The assembly $A$ is the UNGA, which is partitioned into five regions: Africa, Asia, Eastern Europe (EE), the Latin America and Caribbean Group (GRULAC-el Grupo Latinoamericano y Caribeño), and the Western European and Others Group (WEOG). ${ }^{14}$ The ten NPM seats are divided between the five regions: one for EE; two for each of Asia, the GRULAC and the WEOG; and three for Africa.

\subsubsection{The UNSC assignment process}

Let $P M$ be the set of PMs and $O M$ be the set of the remaining 188 "ordinary" members. For simplicity, we imagine that the UNSC votes once per year-an assumption that is inconsequential to our findings, but that allows us to interpret naturally the index of motions, $k$, as an index of time (as motions are indexed in the same way as years). As a PM is guaranteed a seat on the UNSC, we have $p_{i j k}=1$ for $a_{i j} \in P M$. We model the UNSC assignment process for ordinary members by first giving each $a_{i j} \in O M$ a probability, $\rho_{i j} \in$ $[0,1]$ (where $\sum_{a_{i j} \in R_{j}} \rho_{i j}=1$ ), with which it will be assigned to the UNSC if (i) it competes with all other members of its region; and (ii) only a single seat is being assigned.

We construct empirical estimates of the $\rho_{i j}$ from the analysis of Dreher et al. (2014), which estimates empirically the determinants of election to the UNSC as a NPM, accounting for the two-stage process by which such members presently are elected. ${ }^{15}$ These authors show that three country characteristics systematically predict UNSC election: population, gross national income per capita, and waiting time since last serving on the UNSC. The estimated coefficients for these three variables can be used in a straightforward way to compute estimates of the $\rho_{i j}$. ${ }^{16}$ The resulting estimates are shown in Table 1.

To generate the $p_{i j k}$ we feed the empirical estimates of the $\rho_{i j}$ into a computer simulation of the UNSC election process over a set $K^{\prime}$ spanning 100,000 simulated years. The precise details of the simulation will not be of interest to all readers, so these are relegated to the Appendix. As we discuss below, the set of $p_{i j k}$ we obtain in this way are used to estimate the proximity of the UNSC to strong country EVP, and the obtained estimates of the $\bar{p}_{i j}$ (see Table 1) are used to estimate the proximity of the UNSC to weak country EVP.

\footnotetext{
${ }^{14}$ See Table 1 for the full membership of each of the regional groups (excluding PMs). Of the PMs, China is a member in Asia, Russia in EE, and France and the United Kingdom in the WEOG. Technically, the United States is not a member of any regional group, but it attends meetings of the WEOG as an observer and is considered to be a member of that group for electoral purposes (UN 2012). For the purposes of this paper, therefore, we give the United States membership in the WEOG.

15 In the first stage, the regions make nominations to the UNGA and, in the second stage, the UNGA votes. See Dreher et al. (2014) for a detailed account of the election process.

${ }^{16}$ Because the Dreher et al. dataset ends in 2006, we obtain estimates of country populations and gross national incomes per capita (current USD) for 2012 from the CIA World Factbook (see https://www.cia.gov/ library/publications/the-world-factbook/index.html\#). We update Dreher et al.'s variable measuring waiting time since last serving on the UNSC to 2012 using historical membership data from the UNSC Web site (http://www.un.org/Docs/sc). To produce the estimates in Table 1, these data, along with the coefficient values for population, gross national income per capita, and waiting time since last serving on the UNSC reported in their Table 3a, are fed into their Eq. (5), where we assume that the sum in the denominator is over all countries in the region (i.e., their " $E_{j t}$ " — the set of countries competing for the seat-is assumed to be $R_{j t}$ ).
} 
Table 1 Estimated $\left(\rho_{i j}, \bar{p}_{i j}\right)$

\begin{tabular}{|c|c|c|}
\hline & $\rho_{i j}$ & $\bar{p}_{i j}$ \\
\hline \multicolumn{3}{|l|}{ Africa } \\
\hline Algeria & 0.0860 & 0.21008 \\
\hline Morocco & 0.0501 & 0.14208 \\
\hline Nigeria & 0.0497 & 0.13907 \\
\hline Egypt & 0.0424 & 0.12154 \\
\hline Ghana & 0.0384 & 0.11102 \\
\hline Tunisia & 0.0377 & 0.11090 \\
\hline United Republic of Tanzania & 0.0376 & 0.10926 \\
\hline South Africa & 0.0336 & 0.10050 \\
\hline Zimbabwe & 0.0329 & 0.09992 \\
\hline Zambia & 0.0322 & 0.09598 \\
\hline Mozambique & 0.0319 & 0.09548 \\
\hline Kenya & 0.0319 & 0.09436 \\
\hline Senegal & 0.0309 & 0.09200 \\
\hline Mali & 0.0245 & 0.07654 \\
\hline Niger & 0.0226 & 0.06948 \\
\hline Cote d'Ivoire & 0.0220 & 0.06816 \\
\hline Guinea & 0.0218 & 0.06788 \\
\hline Congo & 0.0218 & 0.06742 \\
\hline Ethiopia & 0.0213 & 0.06704 \\
\hline Angola & 0.0198 & 0.06180 \\
\hline Libya & 0.0189 & 0.06026 \\
\hline Uganda & 0.0184 & 0.05822 \\
\hline Burkina Faso & 0.0173 & 0.05374 \\
\hline Malawi & 0.0172 & 0.05372 \\
\hline Madagascar & 0.0170 & 0.05324 \\
\hline Mauritania & 0.0163 & 0.05316 \\
\hline Sudan & 0.0159 & 0.05080 \\
\hline Togo & 0.0150 & 0.04828 \\
\hline Gabon & 0.0147 & 0.04704 \\
\hline Benin & 0.0136 & 0.04424 \\
\hline Namibia & 0.0124 & 0.04001 \\
\hline Mauritius & 0.0121 & 0.03802 \\
\hline Cameroon & 0.0104 & 0.03312 \\
\hline South Sudan & 0.0098 & 0.03206 \\
\hline Botswana & 0.0097 & 0.02964 \\
\hline Sierra Leone & 0.0087 & 0.02920 \\
\hline Lesotho & 0.0087 & 0.02830 \\
\hline Democratic Republic of the Congo & 0.0082 & 0.02516 \\
\hline Eritrea & 0.0072 & 0.02394 \\
\hline Djibouti & 0.0071 & 0.02308 \\
\hline Gambia & 0.0062 & 0.02110 \\
\hline Central African Republic & 0.0061 & 0.02070 \\
\hline Burundi & 0.0059 & 0.01860 \\
\hline
\end{tabular}


Table 1 continued

\begin{tabular}{|c|c|c|}
\hline & $\rho_{i j}$ & $\bar{p}_{i j}$ \\
\hline Rwanda & 0.0055 & 0.01756 \\
\hline Swaziland & 0.0050 & 0.01590 \\
\hline Somalia & 0.0048 & 0.01560 \\
\hline Cape Verde & 0.0045 & 0.01454 \\
\hline Comoros & 0.0030 & 0.01058 \\
\hline Chad & 0.0029 & 0.01038 \\
\hline Guinea-Bissau & 0.0024 & 0.00886 \\
\hline Liberia & 0.0023 & 0.00744 \\
\hline Sao Tome and Principe & 0.0019 & 0.00694 \\
\hline Equatorial Guinea & 0.0012 & 0.00458 \\
\hline Seychelles & 0.0005 & 0.00148 \\
\hline \multicolumn{3}{|l|}{ Asia } \\
\hline India & 0.47728 & 0.51706 \\
\hline Japan & 0.12114 & 0.28257 \\
\hline Pakistan & 0.09212 & 0.23894 \\
\hline Malaysia & 0.04707 & 0.13667 \\
\hline Republic of Korea & 0.04376 & 0.12900 \\
\hline Indonesia & 0.03583 & 0.10664 \\
\hline Bangladesh & 0.02381 & 0.07358 \\
\hline Singapore & 0.01899 & 0.05942 \\
\hline Thailand & 0.01732 & 0.05458 \\
\hline Jordan & 0.01521 & 0.05002 \\
\hline Philippines & 0.01487 & 0.04852 \\
\hline United Arab Emirates & 0.01314 & 0.04120 \\
\hline Sri Lanka & 0.01113 & 0.03650 \\
\hline Iran & 0.00657 & 0.02182 \\
\hline Saudi Arabia & 0.00630 & 0.02040 \\
\hline Kuwait & 0.00579 & 0.01916 \\
\hline Myanmar & 0.00518 & 0.01714 \\
\hline Nepal & 0.00516 & 0.01670 \\
\hline Qatar & 0.00462 & 0.01560 \\
\hline Yemen & 0.00414 & 0.01296 \\
\hline Iraq & 0.00332 & 0.01102 \\
\hline Vietnam & 0.00324 & 0.01102 \\
\hline Oman & 0.00323 & 0.01024 \\
\hline Kazakhstan & 0.00257 & 0.00884 \\
\hline Fiji & 0.00203 & 0.00712 \\
\hline Cyprus & 0.00200 & 0.00696 \\
\hline Papua New Guinea & 0.00196 & 0.00666 \\
\hline Syrian Arab Republic & 0.00168 & 0.00544 \\
\hline Bahrain & 0.00149 & 0.00510 \\
\hline Uzbekistan & 0.00148 & 0.00420 \\
\hline Brunei & 0.00092 & 0.00310 \\
\hline Lebanon & 0.00082 & 0.00262 \\
\hline
\end{tabular}


Table 1 continued

\begin{tabular}{|c|c|c|}
\hline & $\rho_{i j}$ & $\bar{p}_{i j}$ \\
\hline DPR Korea & 0.00076 & 0.00248 \\
\hline Afghanistan & 0.00075 & 0.00240 \\
\hline Cambodia & 0.00062 & 0.00236 \\
\hline Turkmenistan & 0.00060 & 0.00200 \\
\hline Mongolia & 0.00048 & 0.00172 \\
\hline Tajikistan & 0.00044 & 0.00138 \\
\hline Kyrgyzstan & 0.00042 & 0.00122 \\
\hline Laos & 0.00040 & 0.00118 \\
\hline Bhutan & 0.00033 & 0.00106 \\
\hline Maldives & 0.00022 & 0.00076 \\
\hline Solomon Islands & 0.00022 & 0.00076 \\
\hline Timor Leste & 0.00018 & 0.00046 \\
\hline Tonga & 0.00008 & 0.00028 \\
\hline Kiribati & 0.00007 & 0.00024 \\
\hline Vanuatu & 0.00007 & 0.00022 \\
\hline Samoa & 0.00005 & 0.00018 \\
\hline Micronesia (Federeated States of) & 0.00003 & 0.00016 \\
\hline Nauru & 0.00002 & 0.00012 \\
\hline Marshall Islands & 0.00002 & 0.00010 \\
\hline Tuvalu & 0.00002 & 0.00006 \\
\hline Palau & 0.00002 & 0.00006 \\
\hline \multicolumn{3}{|l|}{$E E$} \\
\hline Poland & 0.3681 & 0.29800 \\
\hline Ukraine & 0.2470 & 0.23984 \\
\hline Romania & 0.1122 & 0.12666 \\
\hline Hungary & 0.0591 & 0.06883 \\
\hline Czech Republic & 0.0525 & 0.06436 \\
\hline Belarus & 0.0256 & 0.03156 \\
\hline Serbia & 0.0227 & 0.02902 \\
\hline Bulgaria & 0.0191 & 0.02282 \\
\hline Azerbaijan & 0.0178 & 0.02243 \\
\hline Slovakia & 0.0145 & 0.01816 \\
\hline Croatia & 0.0112 & 0.01412 \\
\hline Republic of Moldova & 0.0078 & 0.00980 \\
\hline Georgia & 0.0074 & 0.00940 \\
\hline Albania & 0.0062 & 0.00804 \\
\hline Lithuania & 0.0060 & 0.00772 \\
\hline Slovenia & 0.0052 & 0.00664 \\
\hline Bosnia and Herzegovina & 0.0047 & 0.00594 \\
\hline Latvia & 0.0037 & 0.00462 \\
\hline TFYR Macedonia & 0.0034 & 0.00434 \\
\hline Armenia & 0.0034 & 0.00420 \\
\hline Estonia & 0.0019 & 0.00262 \\
\hline Montenegro & 0.0005 & 0.00088 \\
\hline
\end{tabular}


Table 1 continued

\begin{tabular}{|c|c|c|}
\hline & $\rho_{i j}$ & $\bar{p}_{i j}$ \\
\hline \multicolumn{3}{|l|}{ GRULAC } \\
\hline Brazil & 0.34235 & 0.46438 \\
\hline Mexico & 0.19389 & 0.36558 \\
\hline Venezuela & 0.16637 & 0.33693 \\
\hline Argentina & 0.08081 & 0.20360 \\
\hline Colombia & 0.04673 & 0.12944 \\
\hline Chile & 0.04251 & 0.11812 \\
\hline Peru & 0.02556 & 0.07396 \\
\hline Ecuador & 0.01801 & 0.05282 \\
\hline Uruguay & 0.01334 & 0.03926 \\
\hline Cuba & 0.01019 & 0.03174 \\
\hline Dominican Republic & 0.00765 & 0.02328 \\
\hline Honduras & 0.00712 & 0.02162 \\
\hline Costa Rica & 0.00605 & 0.01864 \\
\hline Guatemala & 0.00538 & 0.01729 \\
\hline Panama & 0.00484 & 0.01478 \\
\hline Trinidad and Tobago & 0.00458 & 0.01440 \\
\hline Guyana & 0.00415 & 0.01280 \\
\hline Paraguay & 0.00409 & 0.01192 \\
\hline Jamaica & 0.00381 & 0.01142 \\
\hline Nicaragua & 0.00371 & 0.01098 \\
\hline Bolivia & 0.00340 & 0.01024 \\
\hline El Salvador & 0.00165 & 0.00510 \\
\hline Bahamas & 0.00149 & 0.00484 \\
\hline Belize & 0.00070 & 0.00206 \\
\hline Suriname & 0.00061 & 0.00160 \\
\hline Barbados & 0.00046 & 0.00108 \\
\hline Haiti & 0.00020 & 0.00082 \\
\hline Antigua and Barbuda & 0.00015 & 0.00058 \\
\hline Saint Lucia & 0.00013 & 0.00048 \\
\hline Saint Kitts and Nevis & 0.00002 & 0.00012 \\
\hline Saint Vincent and the Grenadines & 0.00002 & 0.00006 \\
\hline Grenada & 0.00001 & 0.00004 \\
\hline Dominica & 0.00001 & 0.00002 \\
\hline \multicolumn{3}{|l|}{$W E O G$} \\
\hline Germany & 0.28949 & 0.40439 \\
\hline Turkey & 0.16346 & 0.30002 \\
\hline Italy & 0.11347 & 0.23468 \\
\hline Spain & 0.07454 & 0.16795 \\
\hline Austria & 0.07041 & 0.16302 \\
\hline Netherlands & 0.04505 & 0.10772 \\
\hline Canada & 0.03614 & 0.09062 \\
\hline Sweden & 0.03072 & 0.07792 \\
\hline Switzerland & 0.02616 & 0.06536 \\
\hline
\end{tabular}


Table 1 continued

Estimates computed from

Table 3a of Dreher et al. (2014). Countries are listed in descending order of $\rho_{i j}$ within each region

\begin{tabular}{lll}
\hline & $\rho_{i j}$ & $\bar{p}_{i j}$ \\
\hline Ireland & 0.02483 & 0.06198 \\
Denmark & 0.02285 & 0.05798 \\
Belgium & 0.02184 & 0.05574 \\
Finland & 0.01849 & 0.04794 \\
Portugal & 0.01692 & 0.04348 \\
Norway & 0.01666 & 0.04302 \\
Australia & 0.01228 & 0.03320 \\
New Zealand & 0.01027 & 0.02716 \\
Greece & 0.00497 & 0.01398 \\
Israel & 0.00054 & 0.00166 \\
Malta & 0.00039 & 0.00100 \\
Luxembourg & 0.00025 & 0.00070 \\
Iceland & 0.00007 & 0.00012 \\
Monaco & 0.00007 & 0.00012 \\
Andorra & 0.00005 & 0.00012 \\
San Marino & 0.00004 & 0.00008 \\
Liechtenstein & 0.00003 & 0.00004 \\
\hline
\end{tabular}

\subsubsection{The UNSC decision rule}

The set of voting possibilities in the UNSC is given by \{for, abstain, against\} and the outcome space by \{pass, fail\}. The UN Charter states that decisions over non-procedural matters are made by an affirmative vote of nine or more members, including the concurring votes of the PMs. A "concurring" vote has come to be understood, in practice, as either an affirmative vote or an abstention (e.g., Blum 2005), so a negative vote by a PM is distinct from an abstention. As commented by Felsenthal and Machover (1997, p. 348), this feature implies that the UNSC's decision rule "cannot be faithfully represented" as a binary one. ${ }^{17}$ This observation notwithstanding, the existing studies of equity in the UNSC cited previously, as well as other precursors in the literature (e.g., Shapley and Shubik 1954; Straffin 1983), model the UNSC's decision rule as binary.

We concur with Felsenthal and Machover that the distinct effects of abstention in the UNSC warrant a decision rule in stage 1 that is consistent with a non-zero level of abstention in stage 3. ${ }^{18}$ This we now develop.

\subsection{Stage 1 decision rule}

To allow for abstention in the UNSC, we consider a voting game for stage 1 in which the set of voting possibilities is ffor, abstain, against \} and the outcome space is \{mandate to

\footnotetext{
17 The same point is also made in Freixas and Zwicker (2003).

${ }^{18}$ In the existing literature, the stage 1 vote is modelled as a $(2,2)$ simple voting game under a simple majority decision rule, i.e., two voting possibilities, two outcomes, a mandate to vote "for" in stage 3 arises if more than half the votes are cast in favor of the motion, and a mandate to vote "against" in stage 3 arises otherwise. Under this implementation, a country always enters the council with a mandate to vote either "for" or "against" and would therefore never abstain.
} 
vote "for" on the council (mandate for), no mandate, mandate to vote "against" on the council (mandate against) $\}$. In the event that "no mandate" obtains, the country (or regional bloc under the RDP) is assumed to abstain in the council.

Several countries we know of, such as Belarus, Denmark, Germany and Hungary, employ rules for referendums that contain a majority threshold provision according to which, for a motion to pass, a minimum threshold of citizens must vote strictly in favor (Côrte-Real and Pereira 2004). ${ }^{19}$ We therefore employ a Trichotomous Majority Threshold (TMT) decision rule, which extends this basic principle. Under the TMT rule, there exists a threshold $\tau \in[0,1]$ such that for "mandate for" to obtain, (i) more citizens must vote "for" than vote "against"; and (ii) at least a proportion $\tau$ of all eligible voters must vote "for". For "mandate against" to obtain, (i) more citizens must vote "against" than vote "for"; and (ii) at least a proportion $\tau$ of all eligible voters must vote "against". In all other eventualities, "no mandate" obtains. How we specify the threshold parameter $\tau$ shall be explained shortly.

\subsection{Absolute voting power}

The stage 1 vote corresponds to a $(3,3)$ simple voting game in the sense of Freixas and Zwicker (2003). ${ }^{20}$ Accordingly, absolute voting power in stage $1, \varphi$, is measured using the "Banzhaf measure for $(j, k)$ simple voting games" given in Definition 3.4 of Freixas $(2005 \mathrm{a}) .^{21}$

To compute $\varphi$ under the TMT decision rule (for UC preferences) requires an understanding of its asymptotic properties with respect to the size of the electorate. For a given $\tau$ and electorate of size $q$, we write $\varphi_{i j}=(q ; \tau)$. Direct evaluation of $\varphi(q ; \tau)$ for a country such as China (for which $q$ exceeds one billion) is computationally infeasible, however. Some special values of $\tau$ do, however, permit simplification; for instance, Lindner (2008, Corollary 4.1) gives $\varphi(q ; 0) \rightarrow(\sqrt{3 / \pi})(1 / \sqrt{q})$ as $q \rightarrow \infty$ under UC preferences. When $\tau=0$, however, the "no mandate" outcome arises with measure zero. ${ }^{22}$ To observe the "no mandate" outcome, we therefore prove a related result for $\varphi(q ; 1 / 3)$.

Proposition 3 Under UC preferences and $\tau=1 / 3$, the absolute voting power of a citizen in stage 1, for an electorate of size q, satisfies

\footnotetext{
19 Other countries, notably Italy, implement a similar rule that requires a quorum for the number of people that vote (rather than not voting), instead of a condition on the number of citizens voting in favor. We do not consider this rule, however, for it is well known that it violates the monotonicity requirement of $(j, k)$ simple voting games (see, e.g., Côrte-Real and Pereira 2004; Freixas and Zwicker 2003, 2009; Herrera and Mattozzi 2010; Uleri 2002). Freixas and Zwicker (2009) offer a "soft quorum" rule that avoids this difficulty, but we know of no examples in which it is used in practice.

20 In this terminology, (3,3) signifies three voting possibilities, and three possible outcomes.

21 In particular, we proceed under what Freixas (2005a) terms the "uniform numeric evaluation". This appears to be the most appropriate choice in this setting, since the author notes (p. 58) that his Banzhaf measure coincides with "the probability that in a randomly chosen $j$-partition citizen $i$ will be in a position to change the outcome by altering his/her vote".

${ }^{22}$ Lindner's result is seen by setting $t=1 / 3, w_{k}=1$ for all $k$ and $w_{a}=1$ in her Eq. (31), then taking the limit $N \rightarrow \infty$.
} 


$$
\varphi\left(q ; \frac{1}{3}\right) \rightarrow \frac{3+2 \sqrt{3}}{4 \sqrt{q \pi}} \text { as } q \rightarrow \infty .
$$

Proposition 3 states that, as $q \rightarrow \infty$, the absolute voting power of a citizen in stage 1 is inversely proportional to $\sqrt{q}$. Thus, our result may be interpreted as an extension of Penrose's (1946) original square-root law for the case in which both the set of voting possibilities and the set of voting outcomes are binary.

The vote in stage 3 corresponds to a $(3,2)$ simple voting game. Under the CDP, $\tau=1 / 3$ implies that countries will vote "for" and "against" with an equal probability, given by $5 / 12 \approx 0.42$. The probability that a country will wish to abstain is therefore $1 / 6 \approx 0.17$. Thus, as seems realistic, abstention is chosen less often than either of the remaining voting possibilities. Under the RDP, regional blocs vote according to these same probabilities.

As the Banzhaf measure of Freixas (2005a) assumes equal probabilities, it cannot be applied to stage 3, however. Instead we employ the "generalized Bz measure" of Lindner (2008), which applies only to $(3,2)$ simple voting games, but which allows for the (common) probability of voting "for" or "against" to differ from the probability of voting "abstain". On the class of $(3,2)$ games, Lindner's measure collapses to that of Freixas when every voting possibility is assigned the same probability. ${ }^{23}$

We write $\omega_{i j}^{\mathrm{CDP}}=\omega_{\mathrm{PM}}$ for $a_{i j} \in P M$ and $\omega_{i j}^{\mathrm{CDP}}=\omega_{\mathrm{OM}}$ for $a_{i j} \in O M$. We compute $\left\{\omega_{\mathrm{OM}}, \omega_{\mathrm{PM}}\right\}$ using the method of generating functions (see, e.g., Freixas 2012). We obtain $\omega_{\mathrm{PM}} \approx 0.0458$ and $\omega_{\mathrm{OM}} \approx 0.0139$, implying that a $\mathrm{PM}$ receives some 3.3 times more voting power than a NPM. ${ }^{24}$ The bloc voting powers are computed similarly as $\omega_{\text {Africa }}^{\mathrm{RDP}}=\omega_{\text {GRULAC }}^{\mathrm{RDP}} \approx 0.05, \omega_{\text {Asia }}^{\mathrm{RDP}}=\omega_{E E}^{\mathrm{RDP}} \approx 0.23$, and $\omega_{W E O G}^{\mathrm{RDP}} \approx 0.27$. Thus, were voting along regional lines, WEOG would exercise around 5.3 times more voting power than Africa and the GRULAC (neither of which have any PMs). We compute the $\varphi_{i j}^{\mathrm{CDP}}$ and $\varphi_{j}^{\mathrm{RDP}}$ using Proposition 3 .

\subsection{Measuring deviations from equitability}

We wish to measure, in an objective sense, the proximity of $\mathcal{C}_{\mathrm{UNSC}}^{2012}$ to each equity concept. We therefore adopt as our metric the "index of distortion" used in Felsenthal and Machover (2004, 2007), and commonly attributed to Loosemore and Hanby (1971). Under this index, the "distance" between two unit vectors $\mathbf{X}$ and $\mathbf{Y}$ is given by $d(\mathbf{X}, \mathbf{Y})=\sum$ $\left|X_{i}-Y_{i}\right| / 2$.

Using Definition 2, we define proximity measures on $\mathcal{C}_{\text {UNSC }}^{2012}$ with respect to our three equity concepts as

$$
\left\|C E_{s}\right\|=1-\mathbf{E}_{K^{\prime}}\left(d\left(\boldsymbol{v}^{C E_{s}}, \lambda\right)\right) ; \quad\left\|C E_{w}\right\|=1-d\left(\boldsymbol{v}^{C E_{w}}, \lambda\right) ; \quad\|R E\|=1-d\left(\boldsymbol{v}^{R E}, \boldsymbol{\lambda}\right) ;
$$

where $v^{C E_{s}}$ is the scaled $|A| \times 1$ unit vector of the $v_{i j}^{C E_{s}} ; v^{C E_{w}}, v^{R E}$ are defined similarly; and $\lambda$ is the $|A| \times 1$ unit vector of the constant $1 /|A|$. Each of these three measures lies on the

\footnotetext{
${ }^{23}$ In this instance, both measures also then correspond to the "absolute Bz index for ternary voting games" of Felsenthal and Machover (1997).

24 In contrast, if all voting possibilities are assumed equally probable, we obtain $\omega_{\mathrm{PM}} \approx 0.10$ and $\omega_{\mathrm{OM}} \approx 0.05$, implying that a PM receives almost exactly twice the voting power of a NPM. When, as in much of the existing literature, the UNSC's decision rule is modelled as binary then $\omega_{\mathrm{PM}} \approx 0.167$ and $\omega_{\mathrm{OM}} \approx 0.017$, which implies that a PM has around ten times more voting power than a NPM.
} 
Table 2 Relative deviations

\begin{tabular}{|c|c|c|c|c|}
\hline \multirow[t]{2}{*}{ Country } & \multicolumn{2}{|l|}{ UC } & \multicolumn{2}{|l|}{$\mathrm{CC}$} \\
\hline & $\mathcal{R}_{i j}^{C E_{w}}$ & $\mathcal{R}_{j}^{R E}$ & $\mathcal{R}_{i j}^{C E_{w}}$ & $\mathcal{R}_{j}^{R E}$ \\
\hline Africa & - & -0.727 & - & -0.765 \\
\hline Algeria & 0.880 & - & 0.530 & - \\
\hline Angola & -0.224 & - & -0.537 & - \\
\hline Benin & -0.242 & - & -0.692 & - \\
\hline Botswana & 0.162 & - & -0.775 & - \\
\hline Burkina Faso & -0.283 & - & -0.602 & - \\
\hline Burundi & -0.644 & - & -0.859 & - \\
\hline Cameroon & -0.601 & - & -0.759 & - \\
\hline Cape Verde & 0.079 & - & -0.896 & - \\
\hline Central African Republic & -0.505 & - & -0.858 & - \\
\hline Chad & -0.839 & - & -0.926 & - \\
\hline Comoros & -0.368 & - & -0.926 & - \\
\hline Congo & 0.780 & - & -0.511 & - \\
\hline Cote d'Ivoire & -0.167 & - & -0.494 & - \\
\hline $\begin{array}{l}\text { Democratic Republic of the } \\
\text { Congo }\end{array}$ & -0.816 & - & -0.795 & - \\
\hline Djibouti & 0.276 & - & -0.836 & - \\
\hline Egypt & -0.274 & - & -0.107 & - \\
\hline Equatorial Guinea & -0.741 & - & -0.970 & - \\
\hline Eritrea & -0.453 & - & -0.829 & - \\
\hline Ethiopia & -0.622 & - & -0.530 & - \\
\hline Gabon & 1.084 & - & -0.651 & - \\
\hline Gambia & -0.180 & - & -0.853 & - \\
\hline Ghana & 0.229 & - & -0.171 & - \\
\hline Guinea & 0.167 & - & -0.496 & - \\
\hline Guinea-Bissau & -0.628 & - & -0.938 & - \\
\hline Kenya & -0.209 & - & -0.312 & - \\
\hline Lesotho & 0.051 & - & -0.788 & - \\
\hline Liberia & -0.776 & - & -0.939 & - \\
\hline Libya & 0.238 & - & -0.573 & - \\
\hline Madagascar & -0.363 & - & -0.604 & - \\
\hline Malawi & -0.237 & - & -0.598 & - \\
\hline Mali & -0.003 & - & -0.466 & - \\
\hline Mauritania & 0.504 & - & -0.618 & - \\
\hline Mauritius & 0.782 & - & -0.722 & - \\
\hline Morocco & 0.307 & - & 0.009 & - \\
\hline Mozambique & 0.061 & - & -0.299 & - \\
\hline Namibia & 0.434 & - & -0.704 & - \\
\hline Niger & -0.043 & - & -0.485 & - \\
\hline Nigeria & -0.415 & - & 0.006 & - \\
\hline Rwanda & -0.719 & - & -0.875 & - \\
\hline Sao Tome and Principe & -0.111 & - & -0.951 & - \\
\hline Senegal & 0.402 & - & -0.324 & - \\
\hline
\end{tabular}


Table 2 continued

\begin{tabular}{|c|c|c|c|c|}
\hline \multirow[t]{2}{*}{ Country } & \multicolumn{2}{|l|}{$\mathrm{UC}$} & \multicolumn{2}{|l|}{$\mathrm{CC}$} \\
\hline & $\mathcal{R}_{i j}^{C E_{w}}$ & $\mathcal{R}_{j}^{R E}$ & $\mathcal{R}_{i j}^{C E_{w}}$ & $\mathcal{R}_{j}^{R E}$ \\
\hline Seychelles & -0.746 & - & -0.990 & - \\
\hline Sierra Leone & -0.350 & - & -0.785 & - \\
\hline Somalia & -0.728 & - & -0.886 & - \\
\hline South Africa & -0.259 & - & -0.283 & - \\
\hline South Sudan & -0.467 & - & -0.770 & - \\
\hline Sudan & -0.536 & - & -0.632 & - \\
\hline Swaziland & -0.220 & - & -0.884 & - \\
\hline Togo & 0.041 & - & -0.651 & - \\
\hline Tunisia & 0.830 & - & -0.190 & - \\
\hline Uganda & -0.452 & - & -0.567 & - \\
\hline United Republic of Tanzania & -0.092 & - & -0.181 & - \\
\hline Zambia & 0.390 & - & -0.313 & - \\
\hline Zimbabwe & 0.463 & - & -0.291 & - \\
\hline Asia & - & -0.371 & - & 0.067 \\
\hline Afghanistan & -0.975 & - & -0.981 & - \\
\hline Bahrain & -0.773 & - & -0.965 & - \\
\hline Bangladesh & -0.679 & - & -0.466 & - \\
\hline Bhutan & -0.939 & - & -0.993 & - \\
\hline Brunei & -0.801 & - & -0.983 & - \\
\hline Cambodia & -0.968 & - & -0.984 & - \\
\hline China & 3.844 & - & 23.032 & - \\
\hline Cyprus & -0.576 & - & -0.948 & - \\
\hline DPR Korea & -0.973 & - & -0.982 & - \\
\hline Fiji & -0.602 & - & -0.950 & - \\
\hline India & -0.212 & - & 2.768 & - \\
\hline Indonesia & -0.625 & - & -0.207 & - \\
\hline Iran & -0.868 & - & -0.845 & - \\
\hline Iraq & -0.903 & - & -0.925 & - \\
\hline Japan & 0.346 & - & 1.068 & - \\
\hline Jordan & 0.030 & - & -0.650 & - \\
\hline Kazakhstan & -0.895 & - & -0.943 & - \\
\hline Kiribati & -0.953 & - & -0.998 & - \\
\hline Kuwait & -0.414 & - & -0.867 & - \\
\hline Kyrgyzstan & -0.977 & - & -0.993 & - \\
\hline Laos & -0.969 & - & -0.989 & - \\
\hline Lebanon & -0.932 & - & -0.981 & - \\
\hline Malaysia & 0.367 & - & -0.004 & - \\
\hline Maldives & -0.918 & - & -0.994 & - \\
\hline Marshall Islands & -0.995 & - & -1.000 & - \\
\hline $\begin{array}{l}\text { Micronesia (Federated States } \\
\text { of) }\end{array}$ & -0.981 & - & -0.999 & - \\
\hline Mongolia & -0.954 & - & -0.990 & - \\
\hline Myanmar & -0.871 & - & -0.878 & - \\
\hline
\end{tabular}


Table 2 continued

\begin{tabular}{|c|c|c|c|c|}
\hline \multirow[t]{2}{*}{ Country } & \multicolumn{2}{|l|}{$\mathrm{UC}$} & \multicolumn{2}{|l|}{$\mathrm{CC}$} \\
\hline & $\mathcal{R}_{i j}^{C E_{w}}$ & $\mathcal{R}_{j}^{R E}$ & $\mathcal{R}_{i j}^{C E_{w}}$ & $\mathcal{R}_{j}^{R E}$ \\
\hline Nauru & -0.958 & - & -0.999 & - \\
\hline Nepal & -0.832 & - & -0.875 & - \\
\hline Oman & -0.638 & - & -0.917 & - \\
\hline Pakistan & -0.033 & - & 0.741 & - \\
\hline Palau & -0.985 & - & -1.000 & - \\
\hline Papua New Guinea & -0.855 & - & -0.948 & - \\
\hline Philippines & -0.740 & - & -0.657 & - \\
\hline Qatar & -0.359 & - & -0.884 & - \\
\hline Republic of Korea & -0.026 & - & -0.076 & - \\
\hline Samoa & -0.973 & - & -0.998 & - \\
\hline Saudi Arabia & -0.794 & - & -0.853 & - \\
\hline Singapore & 0.469 & - & -0.547 & - \\
\hline Solomon Islands & -0.952 & - & -0.995 & - \\
\hline Sri Lanka & -0.588 & - & -0.743 & - \\
\hline Syrian Arab Republic & -0.936 & - & -0.960 & - \\
\hline Tajikistan & -0.974 & - & -0.991 & - \\
\hline Thailand & -0.651 & - & -0.603 & - \\
\hline Timor Leste & -0.971 & - & -0.996 & - \\
\hline Tonga & -0.967 & - & -0.999 & - \\
\hline Turkmenistan & -0.953 & - & -0.985 & - \\
\hline Tuvalu & -0.968 & - & -1.000 & - \\
\hline United Arab Emirates & -0.167 & - & -0.688 & - \\
\hline Uzbekistan & -0.951 & - & -0.965 & - \\
\hline Vanuatu & -0.972 & - & -0.998 & - \\
\hline Vietnam & -0.939 & - & -0.922 & - \\
\hline Yemen & -0.845 & - & -0.896 & - \\
\hline$E E$ & - & 1.156 & - & 0.613 \\
\hline Albania & -0.767 & - & -0.943 & - \\
\hline Armenia & -0.874 & - & -0.970 & - \\
\hline Azerbaijan & -0.596 & - & -0.832 & - \\
\hline Belarus & -0.447 & - & -0.766 & - \\
\hline Bosnia and Herzegovina & -0.843 & - & -0.958 & - \\
\hline Bulgaria & -0.517 & - & -0.819 & - \\
\hline Croatia & -0.638 & - & -0.896 & - \\
\hline Czech Republic & 0.015 & - & -0.551 & - \\
\hline Estonia & -0.903 & - & -0.985 & - \\
\hline Georgia & -0.726 & - & -0.922 & - \\
\hline Hungary & 0.239 & - & -0.465 & - \\
\hline Latvia & -0.833 & - & -0.966 & - \\
\hline Lithuania & -0.760 & - & -0.940 & - \\
\hline Montenegro & -0.962 & - & -0.996 & - \\
\hline Poland & 1.568 & - & 1.171 & - \\
\hline Republic of Moldova & -0.730 & - & -0.930 & - \\
\hline
\end{tabular}


Table 2 continued

\begin{tabular}{|c|c|c|c|c|}
\hline \multirow[t]{2}{*}{ Country } & \multicolumn{2}{|l|}{$\mathrm{UC}$} & \multicolumn{2}{|l|}{$\mathrm{CC}$} \\
\hline & $\mathcal{R}_{i j}^{C E_{w}}$ & $\mathcal{R}_{j}^{R E}$ & $\mathcal{R}_{i j}^{C E_{w}}$ & $\mathcal{R}_{j}^{R E}$ \\
\hline Romania & 0.453 & - & -0.080 & - \\
\hline Russian Federation & 13.709 & - & 23.032 & - \\
\hline Serbia & -0.457 & - & -0.799 & - \\
\hline Slovakia & -0.584 & - & -0.867 & - \\
\hline Slovenia & -0.768 & - & -0.955 & - \\
\hline TFYR Macedonia & -0.822 & - & -0.965 & - \\
\hline Ukraine & 0.865 & - & 0.718 & - \\
\hline GRULAC & - & -0.639 & - & -0.698 \\
\hline Antigua and Barbuda & -0.939 & - & -0.998 & - \\
\hline Argentina & 0.703 & - & 0.479 & - \\
\hline Bahamas & -0.599 & - & -0.968 & - \\
\hline Barbados & -0.857 & - & -0.990 & - \\
\hline Belize & -0.788 & - & -0.984 & - \\
\hline Bolivia & -0.825 & - & -0.925 & - \\
\hline Brazil & 0.779 & - & 2.393 & - \\
\hline Chile & 0.545 & - & -0.127 & - \\
\hline Colombia & 0.007 & - & -0.064 & - \\
\hline Costa Rica & -0.554 & - & -0.868 & - \\
\hline Cuba & -0.495 & - & -0.768 & - \\
\hline Dominica & -0.992 & - & -1.000 & - \\
\hline Dominican Republic & -0.624 & - & -0.838 & - \\
\hline Ecuador & -0.252 & - & -0.611 & - \\
\hline El Salvador & -0.900 & - & -0.966 & - \\
\hline Grenada & -0.993 & - & -1.000 & - \\
\hline Guatemala & -0.781 & - & -0.887 & - \\
\hline Guyana & -0.216 & - & -0.907 & - \\
\hline Haiti & -0.990 & - & -0.996 & - \\
\hline Honduras & -0.573 & - & -0.839 & - \\
\hline Jamaica & -0.612 & - & -0.912 & - \\
\hline Mexico & 0.845 & - & 1.685 & - \\
\hline Nicaragua & -0.763 & - & -0.922 & - \\
\hline Panama & -0.607 & - & -0.899 & - \\
\hline Paraguay & -0.747 & - & -0.912 & - \\
\hline Peru & -0.281 & - & -0.470 & - \\
\hline Saint Kitts and Nevis & -0.995 & - & -1.000 & - \\
\hline Saint Lucia & -0.936 & - & -0.996 & - \\
\hline $\begin{array}{l}\text { Saint Vincent and the } \\
\text { Grenadines }\end{array}$ & -0.984 & - & -0.999 & - \\
\hline Suriname & -0.857 & - & -0.986 & - \\
\hline Trinidad and Tobago & -0.370 & - & -0.900 & - \\
\hline Uruguay & 0.176 & - & -0.705 & - \\
\hline Venezuela & 2.329 & - & 1.449 & - \\
\hline WEOG & - & 0.582 & - & 0.783 \\
\hline
\end{tabular}


Table 2 continued

\begin{tabular}{|c|c|c|c|c|}
\hline \multirow[t]{2}{*}{ Country } & \multicolumn{2}{|l|}{ UC } & \multicolumn{2}{|l|}{$\mathrm{CC}$} \\
\hline & $\mathcal{R}_{i j}^{C E_{w}}$ & $\mathcal{R}_{j}^{R E}$ & $\mathcal{R}_{i j}^{C E_{w}}$ & $\mathcal{R}_{j}^{R E}$ \\
\hline Andorra & -0.974 & - & -0.999 & - \\
\hline Australia & -0.635 & - & -0.764 & - \\
\hline Austria & 1.943 & - & 0.165 & - \\
\hline Belgium & -0.062 & - & -0.580 & - \\
\hline Canada & -0.177 & - & -0.344 & - \\
\hline Denmark & 0.341 & - & -0.568 & - \\
\hline Finland & 0.085 & - & -0.656 & - \\
\hline France & 20.859 & - & 23.032 & - \\
\hline Germany & 1.373 & - & 1.942 & - \\
\hline Greece & -0.801 & - & -0.909 & - \\
\hline Iceland & -0.977 & - & -0.998 & - \\
\hline Ireland & 0.566 & - & -0.548 & - \\
\hline Israel & -0.972 & - & -0.990 & - \\
\hline Italy & 0.617 & - & 0.720 & - \\
\hline Liechtenstein & -0.966 & - & -0.999 & - \\
\hline Luxembourg & -0.958 & - & -0.996 & - \\
\hline Malta & -0.931 & - & -0.994 & - \\
\hline Monaco & -0.960 & - & -0.999 & - \\
\hline Netherlands & 0.439 & - & -0.199 & - \\
\hline New Zealand & -0.304 & - & -0.801 & - \\
\hline Norway & 0.051 & - & -0.683 & - \\
\hline Portugal & -0.299 & - & -0.687 & - \\
\hline San Marino & -0.976 & - & -0.999 & - \\
\hline Spain & 0.319 & - & 0.224 & - \\
\hline Sweden & 0.335 & - & -0.441 & - \\
\hline Switzerland & 0.288 & - & -0.513 & - \\
\hline Turkey & 0.875 & - & 1.186 & - \\
\hline United Kingdom & 21.329 & - & 23.032 & - \\
\hline United States of America & 8.982 & - & 23.032 & - \\
\hline
\end{tabular}

unit interval, with unity indicating maximal proximity, and zero indicating the minimum possible proximity.

To gain further insight, we decompose the proximity measures for $C E_{w}$ and $R E$ by country (Table 2). Specifically, we report individual relative deviations, $\mathcal{R}$, from these equity concepts as ${ }^{25}$ :

${ }^{25}$ An analogous relative deviation from strong country EVP is given by $\mathcal{R}_{i j}^{C E_{s}}=\mathbf{E}_{K^{\prime}}\left\{\left|v_{i j k}^{C E_{s}}-\mathbf{E}_{A}\left(v_{i j k}^{C E_{s}}\right)\right| / \mathbf{E}_{A}\left(v_{i j k}^{C E_{s}}\right)\right\}$. This measure considers the absolute value of deviations from the mean such that positive and negative deviations do not offset over time. As, however, we observe a high degree of correlation between $\mathcal{R}_{i j}^{C E_{s}}$ and the absolute value of $\mathcal{R}_{i j}^{C E_{w}}$ across countries we choose, in the interest of brevity, to omit the results for $\mathcal{R}_{i j}^{C E_{s}}$. 


$$
\mathcal{R}_{i j}^{C E_{w}}=\mathbf{E}_{K^{\prime}}\left(\frac{v_{i j k}^{C E_{s}}-\mathbf{E}_{A}\left(v_{i j k}^{C E_{s}}\right)}{\mathbf{E}_{A}\left(v_{i j k}^{C E_{s}}\right)}\right) ; \quad \mathcal{R}_{i j}^{R E}=\frac{v_{i j}^{R E}-\mathbf{E}_{A}\left(v_{i j}^{R E}\right)}{\mathbf{E}_{A}\left(v_{i j}^{R E}\right)} .
$$

\subsection{Results}

Our proximity measures under UC preferences are found as

$$
\left\|C E_{s}\right\|=0.38 ; \quad\left\|C E_{w}\right\|=0.51 ; \quad\|R E\|=0.65 .
$$

The maximum deviation is observed to be from strong country EVP. Part of this inequity owes to the two-year term length of a NPM, which implies that countries half-way through their terms are assigned to the UNSC with probability one (and thereby wield too much expected voting power in that year). A second explanatory factor is the rule that prevents NPMs from running for immediate reelection, which implies that countries at the end of their terms as NPMs receive an assignment probability of zero (and thereby wield too little expected voting power in that year). As these two factors go in different directions, deviations from equitability offset each other partially over time: comparing $\left\|C E_{s}\right\|$ with $\left\|C E_{w}\right\|$ we see that around $23 \%$ of all deviations from strong country EVP are offset in this way. The equity concept closest to being met is $R E$, suggesting that the UNSC is more equitable from a regional perspective than from a country perspective.

\subsubsection{Country equity}

To delve deeper, we now consider the individual country relative deviations reported in Table 2, beginning with an analysis of country-level equity in the UNSC. As seen in the first column of the table, far too much expected voting power is given to citizens of PM countries. On average (i.e., under weak country EVP) the United Kingdom wields some 21.3 times its equitable level of expected voting power, and even China wields around 3.8 times too much expected voting power. Why are the PMs so heavily overrepresented? Part of the answer lies in the observation that a PM's veto right gives it more voting power than a NPM. This effect, however, is compounded by a second effect that arises from the fact that a PM always is able to cast a vote on the UNSC, whereas an OM can do so only periodically. Existing approaches to assessing the equitability of the UNSC via the ratio $\omega_{\mathrm{PM}} / \omega_{\mathrm{OM}}$ miss entirely this second effect.

Ordinary members suffer a collective deficit of expected voting power. Only a small proportion of such members exceed their equitable expected voting power under $C E_{w}$, and the largest individual deviations are for members that receive too little expected voting power. For instance, under the estimated assignment probabilities in Table 1, Dominica receives just $0.8 \%$ of its equitable expected voting power. In other regions, countries such as Chad (16.1\%), Samoa (2.7\%), Montenegro (3.8\%) and Liechtenstein (3.4\%) also receive much too little expected voting power.

In summary, the current UNSC deviates significantly from country level equitability, and deviations from $C E_{w}$ in any single year will tend to be significantly more pronounced than the average deviation over time. The fundamental problem is that PMs enjoy the greatest voting power and the largest assignment probabilities, whereas, under country EVP, these margins should be traded-off. From this perspective, the long-term goal of 
reform proposals in respect of the PMs must therefore be to either end their veto rights, end their right to be ever-present on the UNSC, or some combination of the two. Note, however, that our equity measures would permit a PM to exercise a veto when a UNSC member if they were willing to sacrifice sufficient assignment probability. Thus, there is nothing inherent in our country equity concept that supports the abolition of the veto. ${ }^{26}$ If retaining the right of veto, $C E_{w}$ would obtain for China if it were represented on the UNSC in around 24 of every 100 years. The United States would qualify for membership under $C E_{w}$ in only around 12 years in every 100, while the United Kingdom and France would qualify for membership in only around six. On the other hand, in return for receiving the voting power of an OM only, $C E_{w}$ would obtain for India if it were represented in around 76 of every 100 years.

The reason that the above insights are relevant just to the long-term is the impracticality of short- or even medium-term reforms affecting the existing PMs. No PM is willing to relinquish either its right of veto, or its right to be ever present, and the constitutional ability of the PMs to retain these powers seems impregnable. ${ }^{27}$ Short-term reform proposals, therefore, seek to extend the right of veto and/or the right to be ever-present on the Council (Cox 2009). The "winners" of such reforms become overrepresented, however, while the underrepresentation of the many "losers" is exacerbated. Accordingly, as a means of compensating the "losers", reform proposals typically also allow for some expansion of the council's membership. While a full quantitative appraisal of the (many) reform proposals of this type to date is beyond the scope of this study, we show in a companion paper (Gould and Rablen 2014) that they generate always modest, and sometimes negative, net improvements in our measures of equity. Thus, those hoping for a step-change in the equitability of the UNSC in the short-term are likely to be disappointed.

\subsubsection{Regional equity}

We now analyze the UNSC from a regional perspective using the region equity concept (the second column of Table 2). Africa is the most underrepresented region, with only about $28 \%$ of its equitable voting power, Latin America has $36 \%$, and Asia $63 \%$. At the other end of the spectrum, EE and the WEOG are overrepresented. EE receives just over double its equitable voting power, making it the most overrepresented region.

These results imply the existence of substantial inequity between the north-defined in Zifcak (2006, footnote 9) as comprising EE and the WEOG-and the south (Africa, Asia and the GRULAC). If UNSC voting were along north-south lines, the ratio of bloc voting powers in the council would be exactly $1: 1$. As, however, the south is more populous, $R E$ requires that it receive more voting power than the north. Accordingly, the south achieves just $63 \%$ of its equitable voting power. Therefore, the regional equity concepts advocate that voting power should be shifted away from EE and the WEOG, and towards Africa, Asia and the GRULAC.

An approach to reform of the UNSC that could address these regional imbalances in representation effectively is to alter the allocation of NPM seats between regions (possibly in conjunction with an increase in the total number of NPMs). Our regional equity concept is not prescriptive in this regard, however, as only the voting power of the regional bloc

\footnotetext{
${ }^{26}$ For an alternative analysis of the veto from the perspective of bargaining theory, see Winter (1996).

27 The San Francisco Declaration of 1945 ensures that a PM can veto questions of veto rights, for a PM exercises a veto on all non-procedural matters and also on whether a matter is to be deemed procedural or non-procedural (see, e.g., Gross 1953).
} 
matters, so, for a given bloc voting power, the number of countries that form the bloc is irrelevant. Strong country EVP is prescriptive in this regard, however.

Proposition 4 If $\mathcal{C}_{\mathrm{UNSC}}^{2012}$ satisfies strong country EVP then $n_{j} \propto \sum_{a_{i j} \in R_{j}} \frac{\sqrt{q_{i j}}}{\omega_{i j}^{\mathrm{CDP}}}$ for all $j$.

The proof of Proposition 4 first establishes that, under the assumptions of this application, strong EVP implies $p_{i j k} \propto \sqrt{q_{i j}} / \omega_{i j}^{\mathrm{CDP}}$. Then, as must be true by construction, $\sum_{a_{i j} \in R_{j}} p_{i j k}=n_{j}$ and the Proposition follows. According to Proposition 4, the (approximate) optimal $n_{j}$ for the current 15-member UNSC would be: 5.5 members from Asia, four members from Africa, two members from each of the GRULAC and the WEOG, and 1.5 members from EE. ${ }^{28}$ Thus the WEOG, with four seats in the present UNSC, has twice its entitlement under $C E_{s}$, while Asia and Africa-which both receive three seats-are underrepresented, in Asia's case by close to one-half.

From a reform perspective, Proposition 4 suggests that NPM seats should be reallocated away from WEOG towards Africa and Asia (or, that any expansion of the UNSC be suitably tilted towards Africa and Asia). While, again, a detailed analysis is beyond the scope of this paper, we show in Gould and Rablen (2014) that existing reform proposals do not reap the full equity benefits available from expanding the Council, as the proposed allocation of new NPM seats is tilted insufficiently in favor of Africa and Asia.

\subsection{Preference correlation}

We now briefly consider alternative a priori assumptions regarding preference correlation for the UNSC. We note that country behavior suggests very weak a priori grounds for considering RC preferences. For instance, countries on the UNSC do seem to act as distinct entities within regions. Each council member has full sovereignty over how it votes and countries pour large sums of money into campaigns for election to the UNSC (e.g., Malone 2000), suggesting that they do not perceive membership by another country in their region to be a perfect (or even a good) substitute for their own membership. Also, the voting behavior in the UNGA of serving members of the UNSC is no more similar to that of their regional members than to the votes of the remaining UNGA members (Lai and Lefler 2009). With the exception of the WEOG-whose composition partly reflects that of the British Commonwealth (Daws 1999) — the regional groups are not self-selected, but determined solely by an exogenous factor in geographic location. Accordingly, we shall discuss only the case of $\mathrm{CC}$ preferences.

For CC preferences the TMT rule specified in Sect. 3.2 cannot be employed in the context of the RDP, for it does not satisfy anonymity for all regional citizens. ${ }^{29}$ A simple way to permit an analysis of regional equity in this case is to define a counterpart TMT rule at the level of countries - the "Country TMT" (CTMT) rule. For brevity, when the citizens of country $i$ vote $x$ unanimously, we say that "country $i$ voted $x$ ". Under the CTMT rule, for the regional outcome to be "mandate for", (i) more countries must vote "for" than vote "against"; and (ii) at least a proportion $\tau>0$ of all countries must vote "for". A

\footnotetext{
${ }^{28}$ Here the fractional Asia and EE membership would be achieved by alternating between (i) Asia having six seats, and EE one; and (ii) Asia having five seats and EE two.

29 To see this point, note that the stage 1 regional election would see bloc voting among the citizens of each country, but with each bloc voting independently. In this case, within a region, the TMT rule gives more voting power to the citizens of a more populous country than to the citizens of a less populous country.
} 
symmetric condition applies for "mandate against" to obtain, with "no mandate" obtaining in all other eventualities. For comparability, we again assume $\tau=1 / 3$.

Using the above approach, the proximity measures for CC preferences are found as:

$$
\left\|C E_{s}\right\|=0.24 ; \quad\left\|C E_{w}\right\|=0.31 ; \quad\|R E\|=0.71 .
$$

Country equity falls in comparison to the results under UC preferences. In the third column of Table 2, we see that the least populous countries warrant larger expected voting powers under CC preferences than they do under UC preferences, whereas the most populous countries (including the PMs) warrant lesser expected voting powers. Accordingly, the least populous countries become even more heavily underrepresented, while the PMs become even more heavily overrepresented.

Proximity to $R E$ is, however, improved under $\mathrm{CC}$ preferences. This arises as, under UC preferences, regional equity in the UNSC requires that voting power reflect (inversely) the population of each region. This results in inequity as the regions vary greatly in population, while voting power in the UNSC is relatively flat across regional blocs. Under CC preferences, however, regional equity in the UNSC requires that voting power reflect the number of countries in each region. This reduces inequity as there is less variability across regions in the number of countries per region than in the regional populations.

\section{Conclusion}

The councils of the United Nations play important roles in upholding global wealth, health, law and security. Yet, to our knowledge, no previous analysis has developed formal equity principles for the analysis of such bodies, in which only a subset of members may vote at a point in time. We formulate democratic equity concepts for such bodies in a new class of voting game we term a council voting game. In particular, we develop separate notions of equity for such games at both the country and region levels.

We demonstrate the utility of our theoretical framework with an application to the United Nations Security Council (UNSC). We find that significant degrees of inequity exist in the long-run average levels of representation across countries, and that these deviations from long-run equitability typically are exacerbated in any single iteration of the UNSC viewed in isolation. Exploiting our distinction between country and regional notions of equity, we also find that the UNSC is more inequitable if its members are viewed as representing only themselves, than if they are viewed as representing their region as a whole. We emphasize that, in our framework, the excessive representation of the UNSC's permanent members (PMs) derives from their right to be ever-present on the UNSC, not only from their right of veto. Our measure of regional equity suggests that Africa (not Asia) is the most heavily underrepresented region, while Eastern (not Western) Europe is the most heavily overrepresented region.

What do our findings imply for the ongoing debate on UNSC reform? First, we believe our framework clarifies the nature of the underlying tradeoffs. Simultaneous achievement of country and regional equity is infeasible and, for the time-being at least, realpolitik rules out the types of reforms needed to address the overrepresentation of the permanent members. Second, our analysis highlights that, in the long-run, reform of the UNSC must address not only the distribution of voting power, but also the distribution of assignment probabilities. 
The apparent tension between realpolitik and the equity concepts we develop suggests that the latter should be understood purely as normative benchmarks against which to assess the equitability of alternative reform possibilities. An avenue for future research might, therefore, be to investigate "second-best" designs that minimize deviations from our equity concepts under an additional realpolitik constraint. While this idea must await a proper treatment, we hope the present contribution marks a first step in the normative analysis of democratic equitability in councils.

Acknowledgments We thank Georg Vanberg (Associate Editor), three anonymous referees, Axel Dreher, Christoph Mikulaschek, Jim Vreeland, Matthias Weber; the participants of the Jan Tinbergen European Peace Science Conference (Warwick), PEIO (Berlin), the European Public Choice Society Conference (Cambridge) and the Voting Power Analysis with Reference to Institutions of Global Governance workshop (Warwick) for helpful comments on earlier versions of the paper. Gould thanks the University of Westminster for financial support.

Open Access This article is distributed under the terms of the Creative Commons Attribution 4.0 International License (http://creativecommons.org/licenses/by/4.0/), which permits unrestricted use, distribution, and reproduction in any medium, provided you give appropriate credit to the original author(s) and the source, provide a link to the Creative Commons license, and indicate if changes were made.

\section{Appendix}

Proof of Proposition 1 Under the CDP, and assuming UC preferences, we have $v_{i j k}^{C E_{s}}=\varphi_{i j}^{\mathrm{CDP}} p_{i j k} \omega_{i j}^{\mathrm{CDP}}$. To equalize $v_{i j k}^{C E_{s}}$ across world citizens there must exist a $\lambda>0$ such that $\omega_{i j}^{\mathrm{CDP}}=\lambda /\left(p_{i j k} \varphi_{i j}^{\mathrm{CDP}}\right)$, which is equivalent to the statement in the Proposition. Parts (ii) and (iii) follow from similar reasoning.

Proof of Proposition 2 (i) Under the CDP, and assuming CC preferences, we have $v_{i j k}^{C E_{s}}=\bar{\varphi}^{\mathrm{CDP}} p_{i j k} \omega_{i j}^{\mathrm{CDP}}$. To equalize $v_{i j k}^{C E_{s}}$ across world citizens there must exist a $\lambda>0$ such that $\omega_{i j}^{\mathrm{CDP}}=\lambda / p_{i j k}$, which is equivalent to the statement in the Proposition. Parts (ii) and (iii) follow from similar reasoning.

Proof of Proposition 3 Citizen $i$ is "critical" when, by reducing his/her support for the motion by one level, the voting outcome is changed. Citizen $i$ is critical in the stage 1 vote under the TMT rule when any of the following holds:

$$
\begin{aligned}
& \mid \text { For }|=| \text { Against } \mid \text { and } \mid \text { Abstain } \mid<\frac{q}{3} ; \\
& \mid \text { For }|=| \text { Against } \mid+1 \text { and } \mid \text { Abstain } \mid<\frac{q}{3} ; \\
& \mid \text { For }|=| \text { Against } \mid-1 \text { and } \mid \text { Abstain } \mid<\frac{q}{3} ; \\
& \mid \text { For } \mid=\left\lfloor\frac{q}{3}\right\rfloor \text { and } \mid \text { Against } \mid<\frac{q}{3} ; \\
& \mid \text { For } \mid<\frac{q}{3} \text { and } \mid \text { Against } \mid=\left\lfloor\frac{q}{3}\right\rfloor .
\end{aligned}
$$

Thus, under the "uniform numeric evaluation" of Freixas (2005a), citizen $i$ is critical if, when changing his/her vote from "for" to "abstain" or from "abstain" to "against", the outcome of the vote also is changed in the same direction. Under the first condition in (A.1), if citizen $i$ votes "for" the outcome is "mandate for", if citizen $i$ votes "against" the 
outcome is "mandate against", and if citizen $i$ votes "abstain" the outcome is "no mandate". In this case citizen $i$ is critical when changing his/her vote from "for" to "abstain" or from "abstain" to "against", leading to an overall contribution to the Banzhaf score of two for votes satisfying this condition. Under the second condition, if citizen $i$ votes "for" or "abstain" the outcome is "no mandate", and if citizen $i$ votes "against" the outcome is "mandate against". Hence, this instance of criticality contributes one to the Banzhaf score. Similarly, under the third condition citizen $i$ can change the result to "mandate against" from "no mandate". Again it contributes one. Under the fourth condition, if citizen $i$ votes "against" or "abstain" the outcome is "no mandate", and if citizen $i$ votes "for" the outcome is "mandate for". Hence this contributes one towards the Banzhaf score. The fifth condition contributes one in the same way as the fourth.

Define i.i.d. random variables $X_{i}, i=1,2 \ldots, q$ by:

$$
X_{i}(x)= \begin{cases}1 & \text { if } x=\text { For } \\ 0 & \text { if } x=\text { Abstain } \\ -1 & \text { if } x=\text { Against }\end{cases}
$$

where $\operatorname{Pr}(x=$ For $)=\operatorname{Pr}(x=$ Abstain $)=\operatorname{Pr}(x=$ Against $)=1 / 3$. Then we have $\mathbf{E}\left(X_{i}\right)=0$ and $\operatorname{Var}\left(X_{i}\right)=2 / 3$, where $X_{i}$ represents the vote of citizen $i$ in stage 1 . Construct another random variable $X^{q}=\sum_{k=1}^{q} X_{k}-X_{i}$, which represents the possible votes from an electorate of size $q$, excluding the vote of citizen $i . X^{q}$ takes integer values corresponding to the difference between the number of "for" and "against" votes, (excluding $i$ 's vote). Then $\mu_{q}=\mathbf{E}\left(X^{q}\right)=0$ and $\left(\sigma_{q}\right)^{2}=\operatorname{Var}\left(X^{q}\right)=2(q-1) / 3$. Let $\phi$ denote the density function of the standard normal distribution. By application of the local central limit theorem (see, e.g., Petrov 1975, Theorem 1) we obtain:

$$
\begin{gathered}
\operatorname{Pr}(\mid \text { For }|=| \text { Against } \mid)=\operatorname{Pr}\left(X^{q}=0\right)=\frac{1}{\sigma_{q}} \phi\left(\frac{0-\mu_{q}}{\sigma_{q}}\right) \sim \frac{1}{\sqrt{4(q-1) \pi / 3}} ; \\
\operatorname{Pr}(\mid \text { For }|=| \text { Against } \mid+1)=\operatorname{Pr}\left(X^{q}=1\right)=\frac{1}{\sigma_{q}} \phi\left(\frac{1-\mu_{q}}{\sigma_{q}}\right) \sim \frac{1}{\sqrt{4(q-1) \pi / 3}} ; \\
\operatorname{Pr}(\mid \text { For }|=| \text { Against } \mid-1)=\operatorname{Pr}\left(X^{q}=-1\right)=\frac{1}{\sigma_{q}} \phi\left(\frac{-1-\mu_{q}}{\sigma_{q}}\right) \sim \frac{1}{\sqrt{4(q-1) \pi / 3}} ;
\end{gathered}
$$

where $\sim$ denotes asymptotic equivalence. The probabilities $\operatorname{Pr}(|\mathrm{For}|=\lfloor q / 3\rfloor)$ and $\operatorname{Pr}(\mid$ Against $\mid=\lfloor q / 3\rfloor)$ cannot be computed from $X^{q}$ as given above. For these we consider the random variables $Y_{i}$ and $Z_{i}$ :

$$
Y_{i}(x)=\left\{\begin{array}{ll}
\frac{2}{3} & \text { if } x=\text { For; } \\
-\frac{1}{3} & \text { if } x=\text { Abstain or Against; }
\end{array} Z_{i}(x)= \begin{cases}\frac{2}{3} & \text { if } x=\text { Against } \\
-\frac{1}{3} & \text { if } x=\text { For or Abstain }\end{cases}\right.
$$

and construct $Y^{q}$ and $Z^{q}$ in the same manner as $X^{q}$. We compute the (common) mean and variance of these random variables to be $\tilde{\mu}_{q}=\mathbf{E}\left(Y^{q}\right)=\mathbf{E}\left(Z^{q}\right)=0$ and $\left(\tilde{\sigma}_{q}\right)^{2}=\operatorname{Var}\left(Y^{q}\right)=\operatorname{Var}\left(Z^{q}\right)=2(q-1) / 9$. Applying the local central limit theorem in a manner similar to above we find that 


$$
\begin{gathered}
\operatorname{Pr}\left(\mid \text { For } \mid=\left\lfloor\frac{q}{3}\right\rfloor\right) \sim \operatorname{Pr}\left(Y^{q}=0\right)=\frac{1}{\tilde{\sigma}_{q}} \varphi\left(\frac{0-\tilde{\mu}_{q}}{\tilde{\sigma}_{q}}\right) \sim \frac{3}{\sqrt{4(q-1) \pi}} ; \\
\operatorname{Pr}\left(\mid \text { Against } \mid=\left\lfloor\frac{q}{3}\right\rfloor\right) \sim \operatorname{Pr}\left(Z^{q}=0\right)=\frac{1}{\tilde{\sigma}_{q}} \varphi\left(\frac{0-\tilde{\mu}_{q}}{\tilde{\sigma}_{q}}\right) \sim \frac{3}{\sqrt{4(q-1) \pi}} .
\end{gathered}
$$

Notice that $\operatorname{Pr}(|\mathrm{For}|=\mid$ Against $\mid$ and $\mid$ Abstain $\mid<q / 3)=\operatorname{Pr}(\mid$ For $|=|$ Against $\mid$ and $\mid$ Abstain $\mid \geq q / 3)$ and therefore $\operatorname{Pr}(\mid$ For $|=|$ Against $\mid$ and $\mid$ Abstain $\mid<q / 3)=\operatorname{Pr}(\mid$ For $\mid=$ $\mid$ Against $\mid$ /2, with similar equivalences holding for the remaining conditions in (A.1). Then

$$
\begin{aligned}
\varphi(q ; 1 / 3)= & \left.4 \operatorname{Pr}\left(\mid \text { For }|=| \text { Against } \mid \text { and } \mid \text { Abstain } \mid<\frac{q}{3}\right)+2 \operatorname{Pr}\left(\mid \text { For }|=| \frac{q}{3}\right\rfloor \text { and } \mid \text { Against } \mid<\frac{q}{3}\right) \\
& \sim \frac{1}{2} \frac{1}{2} \frac{1}{\sqrt{4(q-1) \pi / 3}}+\frac{1}{2} \frac{2}{2} \frac{3}{\sqrt{4(q-1) \pi}} \sim \frac{3+2 \sqrt{3}}{4 \sqrt{q \pi}}
\end{aligned}
$$

Proof of Proposition 4 From Proposition 1, strong country EVP holds if and only if $p_{i j k} \omega_{i j}^{\mathrm{CDP}} \propto 1 / \varphi_{i j}^{\mathrm{CDP}}$. From Proposition $3, \varphi_{i j}^{\mathrm{CDP}} \propto 1 / \sqrt{q_{i j}}$ holds under the specification of $\mathcal{C}_{\mathrm{UNSC}}^{2012}$, so strong country EVP holds in this game if $p_{i j k} \propto \sqrt{q_{i j}} / \omega_{i j}^{\mathrm{CDP}}$ for all $a_{i j}$. Then, as $\sum_{a_{i j} \in R_{j}} p_{i j k}=n_{j}$ by construction, it must hold that $n_{j} \propto \sum_{a_{i j} \in R_{j}} \sqrt{q_{i j}} / \omega_{i j}^{\mathrm{CDP}}$ for all $j$.

\section{Simulation model}

We compute a set of $p_{i j k}$ and a finite-sample estimate of the $\bar{p}_{i j}$ from the realization (by computer simulation) of $\mathcal{C}_{\text {UNSC }}^{2012}$ over the finite set of motions $K^{\prime}=\left\{k_{1}, \ldots, k_{100,000}\right\}$. Precisely, we realize slightly more than 100,000 periods, but discard the very earliest periods. This is necessary as we begin with a UNSC containing the five PMs and ten vacant seats. In each period we elect five new NPMs, hence, it is not until the completion of the election in period two that no vacant seats remain on the elected UNSC. We discard the first four periods as, in all periods beyond the fourth, the elected UNSC contains no vacant seats, and eligibility for election to the UNSC does not depend upon whether a country was elected to the UNSC in either of periods one or two.

We follow the actual timing of UNSC elections: the term of the single EE NPM begins in even years; the two NPMs of the WEOG begin their terms in odd years; and the terms for the two NPMs of the GRULAC are staggered; one is elected each year. Asia's two NPM seats are staggered similarly. The three Africa NPM seats likewise are staggered with two terms beginning in even years and one term beginning in odd years. In practice, the UNGA elects OMs to the UNSC simultaneously when it must choose more than one NPM from the same region in a given year. For the purposes of developing a tractable simulation model, however, we suppose that, in this circumstance, countries are elected sequentially, one-by-one. Hence, if two seats are to be assigned to members of region $j$, then, in each of two rounds, a new realization of a random variable is drawn such that, if all countries in the region are competing for the seat, country $a_{i j}$ is elected with probability $\rho_{i j}$. Because, however, UNSC's rules prohibit countries from having dual membership, if the same country is elected in both rounds the result is annulled and the process repeated again in full. This continues until distinct countries are elected. 
Thus, in a given year, a first set of countries, those halfway through their two-year term, gain automatic renewal of their NPM status in the following year $\left(Y_{k}\right)$; a second set of countries, $I_{k}$, are those ineligible for election to the UNSC in the following year (UNSC rules prohibit NPMs from seeking immediate reelection); and a final set of countries is eligible for election to the UNSC $\left(E_{k}\right)$. Hence, we can write

$$
p_{i j k}\left\{\begin{array}{cl}
=0 & \text { if } a_{i j} \in I_{k} \\
\in(0,1) & \text { if } a_{i j} \in E_{k} \\
=1 & \text { if } a_{i j} \in Y_{k}
\end{array}\right.
$$

For $a_{i j} \in E_{k}$, let $p_{i j k}^{z}$ denote $p_{i j k}$ when $z$ NPM seats are being elected in region $j$, in which case

$$
p_{i j k}^{0}=0 ; \quad p_{i j k}^{1}=\frac{\rho_{i j}}{\sum_{a_{i j} \in E_{j k}} \rho_{i j}} ; \quad p_{i j k}^{2}=\frac{2 p_{i j k}^{1}\left(1-p_{i j k}^{1}\right)}{1-\sum_{a_{i j} \in E_{j k}}\left(p_{i j k}^{1}\right)^{2}}
$$

Note that the numerator of $p_{i j k}^{2}$ is the binomial probability of observing a distinct country pair containing $a_{i j}$, and that the denominator corrects for the impossibility of a country obtaining dual UNSC membership. To compute unbiased estimates of the $\bar{p}_{i j}$ we then simply observe the proportion of the 100,000 motions for which $a_{i j} \in M$ (see Table 1 ).

\section{References}

Annan, K. A. (2005). In larger freedom: Towards development, security and human rights for all, A/59/ 2005. New York: United Nations.

Banzhaf, J. F. (1968). One man, 3.312 votes: A mathematical analysis of the Electoral College. Villanova Law Review, 13(2), 304-332.

Birkmeier, O., Käufl, A., \& Pukelsheim, F. (2011). Abstentions in the German Bundesrat and ternary decision rules in weighted voting systems. Statistics and Risk Modeling, 28(1), 1-16.

Blum, Y. Z. (2005). Proposals for UN Security Council Reform. American Journal of International Law, 99(3), 632-649.

Braham, M., \& Steffen, F. (2002). Voting power in games with abstentions. In M. J. Holler, H. Kliemt, D. Schmidtchen, \& M. E. Streit (Eds.), Jahrbuch für neue politische ökonomie: Band 20: Power and fairness (pp. 333-348). Tübingen: Mohr-Siebeck.

Côrte-Real, P. P., \& Pereira, P. T. (2004). The voter who wasn't there: Referenda, representation and abstention. Social Choice and Welfare, 22(2), 349-369.

Cowling, K., Sacchetti, S., Sugden, R., \& Wilson, J. R. (2010). The United Nations and democratic globalization: A reconnaissance of the issues. In J. B. Davis (Ed.), Global social economy: Development, work and policy (pp. 42-57). Abingdon: Routledge.

Cox, B. (2009). United Nations Security Council reform: Collected proposals and possible consequences. South Carolina Journal of International Law and Business, 6(1), 89-127.

Daws, S. (1999). The origins and development of UN electoral groups. In R. Thakur (Ed.), What is equitable geographic representation in the 21st century? (pp. 11-29). Tokyo: United Nations University.

De Cremer, D., Brockner, J., Fishman, A., van Dijke, M., van Olffen, W., \& Mayer, D. M. (2010). When do procedural fairness and outcome fairness interact to influence employees' work attitudes and behaviors? The moderating effect of uncertainty. Journal of Applied Psychology, 95(2), 291-304.

Dixon, W. J. (1983). The evaluation of weighted voting schemes for the United Nations General Assembly. International Studies Quarterly, 27(3), 295-314.

Dreher, A., Gould, M., Rablen, M. D., \& Vreeland, J. R. (2014). The determinants of election to the United Nations Security Council. Public Choice, 158(1-2), 51-83. 
Dunleavy, P. (2010). The distribution of power across parties in parliament. London: LSE Online.

Fassbender, B. (2004). Pressure for Security Council reform. In D. M. Malone (Ed.), The UN Security Council: From the cold war to the 21st century (pp. 341-356). Colorado: Lynne Rienner.

Felsenthal, D. S., \& Machover, M. (1997). Ternary voting games. International Journal of Game Theory, 26(3), 335-351.

Felsenthal, D. S., \& Machover, M. (1998). The measurement of power: Theory and practice, problems and paradoxes. Cheltenham: Edward Elgar.

Felsenthal, D. S., \& Machover, M. (2001). The Treaty of Nice and qualified majority voting. Social Choice and Welfare, 18(3), 431-464.

Felsenthal, D. S., \& Machover, M. (2003). The voting power approach: Response to a philosophical reproach. European Union Politics, 4(4), 473-479.

Felsenthal, D. S., \& Machover, M. (2004). Analysis of QM rules in the draft constitution for Europe proposed by the European Convention, 2003. Social Choice and Welfare, 23(1), 1-20.

Felsenthal, D. S., \& Machover, M. (2007). Analysis of QM rule adopted by the Council of the European Union. London: LSE Online.

Franck, T. M. (2003). What happens now? The United Nations after Iraq. American Journal of International Law, 97(3), 607-620.

Freixas, J. (2005a). Banzhaf measures for games with several levels of approval in the input and output. Annals of Operations Research, 137(1), 45-66.

Freixas, J. (2005b). The Shapley-Shubik power index for games with several levels of approval in the input and output. Decision Support Systems, 39(2), 185-195.

Freixas, J. (2012). Probabilistic power indices for voting rules with abstention. Mathematical Social Sciences, 64(1), 89-99.

Freixas, J., \& Zwicker, W. S. (2003). Weighted voting, abstention, and multiple levels of approval. Social Choice and Welfare, 21(3), 399-431.

Freixas, J., \& Zwicker, W. S. (2009). Anonymous yes-no voting with abstention and multiple levels of approval. Games and Economic Behavior, 67(2), 428-444.

Frey, B. S., \& Stutzer, A. (2006). Strengthening the citizens' role in international organizations. Review of International Organizations, 1(1), 27-43.

Gould, M., \& Rablen, M. D. (2014). Reform of the United Nations Security Council: Equity and efficiency. Working Paper No. 4818, CESifo, Munich.

Gross, L. (1953). The double veto and the four-power statement on voting in the Security Council. Harvard Law Review, 67(2), 251-280.

Hammer, C. (2002). Reforming the U.N. Security Council: Open letter to U.N. Secretary General Kofi Annan. Florida Journal of International Law, 15(2), 261-272.

Herrera, H., \& Mattozzi, A. (2010). Quorum and turnout in referenda. Journal of the European Economic Association, 8(4), 838-871.

Hosli, M. O., Moody, O., O’Donovan, B., Kaniovski, S., \& Little, A. C. H. (2011). Squaring the circle? Collective and distributive effects of United Nations Security Council reform. Review of International Organizations, 6(2), 163-187.

Konovsky, M. A. (2000). Understanding procedural justice and its impact on business organizations. Journal of Management, 26(3), 489-511.

Lai, B., \& Lefler, V. A. (2009). U.N. Security Council nonpermanent membership: Equitable distribution for equitable representation? Working paper, Midwest Political Science Association.

Laruelle, A., \& Widgrén, M. (1998). Is the allocation of power among EU states fair? Public Choice, 94(3-4), 317-340.

Leech, D. (2002a). Designing the voting system for the EU Council of Ministers. Public Choice, 113(3-4), 437-464.

Leech, D. (2002b). Voting power in the governance of the International Monetary Fund. Annals of Operations Research, 109(1-4), 375-397.

Leech, D. (2003). Power indices as an aid to institutional design: The generalised apportionment problem. In M. J. Holler, H. Kliemt, D. Schmidtchen, \& M. E. Streit (Eds.), Jahrbuch für neue politische ökonomie: Band 22: European governance (pp. 107-121). Tübingen: Mohr Siebeck.

Leech, D., \& Leech, R. (2005). Voting power in the Bretton Woods institutions. Homo Oeconomicus, 22(4), $1-23$.

Leech, D., \& Leech, R. (2006). Voting power and voting blocs. Public Choice, 127(3), 293-311.

Leech, D., \& Leech, R. (2013). A new analysis of a priori voting power in the IMF: Recent quota reforms give little cause for celebration. In M. J. Holler \& N. Nurmi (Eds.), Power, voting, and voting power: 30 years after (pp. 389-410). Heidelberg: Springer. 
Lindner, I. (2008). A special case of Penrose's limit theorem when abstention is allowed. Theory and Decision, 64(4), 495-518.

Loosemore, J., \& Hanby, V. J. (1971). The theoretical limits of maximum distortion: Some analytic expressions for electoral systems. British Journal of Political Science, 1(4), 467-477.

Malone, D. (2000). Eyes on the prize: The quest for nonpermanent seats on the UN Security Council. Global Governance, 6(1), 3-23.

Manno, C. S. (1966). Selective weighted voting in the UN General Assembly: Rationale and methods. International Organization, 20(1), 37-62.

Marchetti, R. (2008). Global democracy: For and against: Ethical theory, institutional design and social struggles. Abingdon: Routledge.

McLean, I., McMillan, A., \& Leech, D. (2005). Duverger's law, Penrose's power index and the unity of the UK. Political Studies, 53(3), 457-476.

Miller, N. R. (2009). A priori voting power and the U.S. Electoral College. Homo Oeconomicus, 26(3-4), 341-380.

Newcombe, H., Wert, J., \& Newcombe, A. (1971). Comparison of weighted voting formulas for the United Nations. World Politics, 23(3), 452-492.

O'Neill, B. (1996). Power and satisfaction in the United Nations Security Council. Journal of Conflict Resolution, 40(2), 219-237.

Penrose, L. S. (1946). The elementary statistics of majority voting. Journal of the Royal Statistical Society, 109(1), 53-57.

Petrov, V. V. (1975). Sums of independent random variables. Heidelberg: Springer.

Rapkin, D. P., \& Strand, J. R. (2006). Reforming the IMF's weighted voting system. The World Economy, 29(3), 305-324.

Rose, A., \& Stevens, B. (1998). A dynamic analysis of fairness in global warming policy: Kyoto, Buenos Aires, and beyond. Journal of Applied Economics, 1(2), 329-362.

Russett, B., O’Neill, B., \& Sutterlin, J. (1996). Breaking the Security Council restructuring logjam. Global Governance, 2(1), 65-80.

Schwartzberg, J. E. (2003). Entitlement quotients as a vehicle for United Nations reform. Global Governance, 9(1), 81-114.

Shapley, L. S. (1962). Simple games: An outline of the descriptive theory. Behavioral Science, 7(1), 59-66.

Shapley, L. S., \& Shubik, M. (1954). A method for evaluating the distribution of power in a committee system. American Political Science Review, 48(3), 787-792.

Straffin, P. D. (1983). Power indices in politics. In S. J. Brams, W. F. Lucas, \& P. D. Straffin (Eds.), Political and related models (pp. 256-321). New York: Springer.

Straffin, P. D. (1993). Game theory and strategy. Washington, DC: The Mathematical Association of America.

Strand, J. R., \& Rapkin, D. P. (2011). Weighted voting in the United Nations Security Council: A simulation. Simulation and Gaming, 42(6), 772-802.

Stutzer, A., \& Frey, B. S. (2006). Making international organizations more democratic. Review of Law and Economics, 1(3), 305-330.

Uleri, P. V. (2002). On referendum voting in Italy: Yes, no or non-vote? How Italian parties learned to control referenda. European Journal of Political Research, 41(6), 863-883.

UN. (2012). United Nations regional groups of member states. New York: United Nations. Retrieved March 9, 2016, from http://www.un.org/depts/DGACM/RegionalGroups.shtml.

UN Secretariat. (2013). Assessment of member states' contributions to the United Nations regular budget for 2014, ST/ADM/SER.B/889. New York: United Nations.

Winter, E. (1996). Voting and vetoing. American Political Science Review, 90(4), 813-823.

Zifcak, S. M. (2006). United Nations reform: Heading north or south? Global Change, Peace \& Security, $18(3), 135-152$. 